\title{
COMPORTAMENTO DOS ELEMENTOS TERRAS RARAS PESADAS EM ZIRCÃO, XENOTIMA E TORITA DE GRANITOS E GREISENS DA SUBPROVÍNCIA ESTANÍFERA PARANÃ, GOIÁS
}

\author{
LUCIANA MIYAHARA TEIXEIRA \& NILSON FRANCISQUINI BOTELHO
}

\begin{abstract}
THEBEHAVIOR OFHEAVYRAREEARTHINZIRCON, XENOTIMEAND THORITEOF GRANITESAND GREISENS OF THE PARANA TIN SUBPROVNCE, GOIAS Two groups of granitic rocks are present in the Paranã Tin Subprovince, gl and g2. Rocks of gl group are older and display an alkalic affinity. g2 granites are metaluminous to peraluminous. Both groups are formed by A-type granites with anomalous REE concentrations, sometimes $\mathrm{IO}^{3}$ greater than the observed in chondrites. In the studied granitic massifs, the raain HREE-bearing minerais are zircon, xenotime and thorite. Zircons from gl and g2 granites show an increase in U, Th, Y and REE during the magmatic evolution. Distinct trends of enrichment in yttrium and REE are observed in zircons from both groups, with a lower REE/Y ratio in gl zircons. During greisenization zircon is reequilibrated, with enrichment in REE. The metamictization degree is stronger in zircons from later granite fácies and greisenized rocks.

Xenotime is a clearly hydrothermal mineral only found in $g l$ greisens. Electron-microprobe data indicate the existence of two groups of xenotime with different range of HREE concentration, $8-13 \%$ and $16-18 \%$.

Thorite is an accessory mineral in granites (group I) and greisens (group II). Group I have lower $\mathrm{Y}_{2} \mathrm{O}_{3}(1-5 \%)$ and $\mathrm{REE} 2 \mathrm{O}_{3}(2-6 \%)$ contents than group II. Group II thorite is probably a hydrothermally reequilibrated magmatic mineral with an enrichment in yttrium $\left(4-7 \% \mathrm{Y}_{2} \mathrm{O}_{3}\right)$ and $\mathrm{REE}$ $\left(7-13 \% \mathrm{REE}_{2} \mathrm{O}_{3}\right)$.

Solid solution between zircon and xenotime was absent in analyzed samples, and the entrance of trivalent cations in zircon is allowed by the substitution: (REE, Y $)^{3+}+\left(\mathrm{SiO}_{3} \mathrm{OH}\right)^{3-} \Leftrightarrow \mathrm{Zr}^{4+}+\left(\mathrm{SiO}_{4}\right)^{4}$. Zircon-thorite and zircon-uraninite solid solutions are present in zircons with higher $\mathrm{U}$ and Th contents. Xenotime-zircon and xenotime-thorite solid solutions are absent in studied xenotimes, the only identified substitution being $\mathrm{Y}^{3+} \Leftrightarrow=\mathrm{REE}^{3+}$. High Zr, U, P, Y and HREE contents in thorite indicate the presence of thorite-zircon, thorite-uraninite and thorite-xenotime solid solutions.

Keywords: Heavy rare earth elements, zircon, xenotime, thorite, granite, greisen

RESUMO A Subprovíncia Estanífera Paranã é constituída por dois grupos de granitos: um mais antigo (gl) de tendência alcalina, e outro mais jovem (g2) de caráter metaluminoso a peraluminoso. Ambos apresentam teores anómalos de ETR, em concentrações que ultrapassam IO ${ }^{3}$ vezes as observadas em condritos. Nos maciços estudados os principais concentradores de ETRP são zircão, xenotima e tonta. Os cristais de zircão das suites g 1 e g2 mostram aumento progressivo em U, Th, Y e ETR durante a evolução magmática. Foram observados diferentes trends de enriquecimento em Y e ETR em zircão de ambas as suites, com os dos granitos gl apresentando menor razão ETR/Y. O zircão dos granitos g l e g2 foi reequilibrado durante a greisenização com o seu enriquecimento em ETR. O grau de metamictização é maior no zircão das fácies mais evoluídas e de rochas greisenizadas de ambas as suites. A xenotima é claramente hidrotermal e encontrada apenas nos greisens desenvolvidos sobre os granitos g 1 . Dados de microssonda eletrônica mostraram a existência de dois grupos de xenotima que diferem nos conteúdos de ETRP, 8 a $13 \%$ e 16 a $18 \%$. A tonta é mineral acessório em granitos (grupo I) e greisens (grupo II). A tonta do grupo I é mais pobre em $\mathrm{Y}_{2} \mathrm{O}_{3}(1$ a $5 \%$ ) e $\mathrm{ETR}_{2} \mathrm{O}_{3}(2 \mathrm{a} 6 \%)$ em relação à torita do grupo $\mathrm{H}$. Provavelmente a tonta do grupo II foi reequilibrada hidrotermalmente, com seu ennquecimento em Y $\left(4\right.$ a $\left.7 \% \mathrm{Y}_{2} \mathrm{O}_{3}\right)$ e ETR $\left(7\right.$ a $\left.13 \% \mathrm{ETR}_{2} \mathrm{O}_{3}\right)$.Não foi constatada a solução sólida entre zircão e xenotima nas amostras analisadas, de modo que a entrada de cations trivalentes no zircão se faz pela substituição : (ETR, Y $)^{3+}\left(\mathrm{SiO}_{3} \mathrm{OH}\right)^{3-} \Leftrightarrow \mathrm{Zr}^{4+}\left(\mathrm{SiO}_{4}\right)^{4-}$ As soluções sólidas zircão - torita e zircão - uraninita ocorrem em zircão com elevados conteúdos em U e Th. As soluções sólidas xenotima - zircão e xenotima - torita não foram constatadas na xenotima estudada, onde a única substituição observada é $\mathrm{Y}^{3+} \Leftrightarrow \mathrm{ETR}^{3+}$. Os altos conteúdos em Zr, U, P, Y e ETRP da torita indicam a presença das soluções sólidas torita - zircão, torita - uraninita e torita - xenotima.

Palavras - chave: Elementos terras raras oesadas. zircão. xenotima. torita. eranito. ereisen
\end{abstract}

INTRODUÇ̃̃O Os maciços graníticos da Província Estanífera de Goiás, Subprovíncia Paranã, caracterizam-se por apresentarem teores anómalos de Elementos Terras Raras (ETR), com concentrações de até $0,2 \%$ de Y + ETR em rocha total, e conteúdos em ETR que ultrapassam 10 vezes os observados em condritos (Marini \& Botelho 1986, Botelho 1992, Marini et al1992). A apatita magmática pode conter até $9 \%$ de ETR e Y, concentrações que podem atingir $16 \%$ quando é reequilibrada hidrotermalmente, apresentando então substituição por britholita - $(\mathrm{Ca}, \mathrm{ETR}, \mathrm{Y})_{5}\left[(\mathrm{Si}, \mathrm{P}) \mathrm{O}_{4}\right]_{3}(\mathrm{OH}, \mathrm{F})$ (Botelho 1992, Botelho \& Teixeira 1996, Teixeira 1998). Os aluviões com cassiterita são ricos em zircão e, na fração inferior a 200 mesh, são mais ricos em zircão do que em cassiterita.

$\mathrm{O}$ estudo dos ETR em minerais permitiu caracterizar aspectos importantes da mineralogia desses granitos, como, por exemplo, a determinação das principais fases acessórias portadoras de ETR e a compreensão do comportamento dessas fases durante, a evolução magmática e a greisenização.

Nos maciços estudados (Soledade, Pedra Branca, Mocambo e Serra do Mendes), os minerais acessórios portadores de ETR são zircão, xenotima, torita, apatita, monazita, allanita, fluocerita e fluorcarbonatos de ETR. Dentre os minerais acessórios zircão, xenotima e torita são os principais concentradores de Elementos Terras Raras Pesadas (ETRP), com conteúdos de até 17\% (Teixeira 1998).

GEOLOGIA LOCAL A Subprovíncia Paranã, pertencente à Província Estanífera de Goiás (Marini e Botelho 1986), localiza-se na porção nordeste do estado de Goiás, próximo à cidade de Teresina de Goiás (Fig. 1). É constituída por oito corpos graníticos, dentre os quais os mais importantes são Soledade, Sucuri, Pedra Branca, Mangabeira, Mocambo e Serra do Mendes.
Os granitos são intrusivos nas rochas do Complexo Granito-Gnáissico (migmatitos e ortognaisses granodioríticos a tonalíticos) e Formação Ticunzal (paragnaisses e micaxistos), sendo recobertos pelas rochas do Grupo Arai (metavulcânicas, quartzitos e metapelitos). De modo geral, seus contatos com as encaixantes são zonas de eisaIhamento (Fig. 1).

Famílias de granitos da Subprovíncia Paranã Inicialmente, os maciços graníticos da Subprovíncia Paranã foram considerados como homogéneos, constituídos de um biotita granito porfirítico com importantes zonas de alteração metassomática (granitos greisenizados, greisens e albititos) (Padilha \& Laguna 1984, Botelho 1984, Marini \& Botelho 1986). Estudos petrográficos e geoquímicos de detalhe realizados por Botelho (1992) permitiram individualizar duas suites de granitos, denominadas de gl e g2, que se distribuem de forma heterogénea nos diversos maciços da região e cujas idades são, respectivamente, 1,7 Ga e 1,6 Ga (Pimentel et al 1991, Botelho e Pimentel 1993). A individualização foi feita com base em parâmetros químicos como as razões $\mathrm{MgO} / \mathrm{TiO}_{2}$ em rocha e ETR/Y em apatita. Ambas são $\leq 1$ nos granitos gl e $>1$ nos granitos g2. As suites gl e g2 são constituídas de granitos do tipo A (Botelho 1992).

Os granitos gl têm tendência alcalina a subalcalina, incompatibilidade de $\mathrm{Nb}$ e Th durante a evolução magmática e alto conteúdo de $\mathrm{Zr}$, Y e ETR. São constituídos, segundo uma evolução magmática crescente, pelas fácies gl a, glb e gl c. Os granitos g2 possuem caráter metaluminoso a peraluminoso, menor razão $\mathrm{K} / \mathrm{Na}$ e $\mathrm{Fe}_{2} \mathrm{O} 3 / \mathrm{MgO}$ e conteúdos em $\mathrm{SiO}_{2}, \mathrm{Al}_{2} \mathrm{O}_{3}$, Li, Sr e Ta mais elevados que os observados nos granitos gl. São constituídos pelas fácies g2b, g2c e g2d (em caráter crescente de evolução magmática) (Botelho 1992).

MÉTODOS ANALÍTICOS Foram confeccionadas aproximadamente 100 lâminas delgadas polidas, procurando abranger o maior 


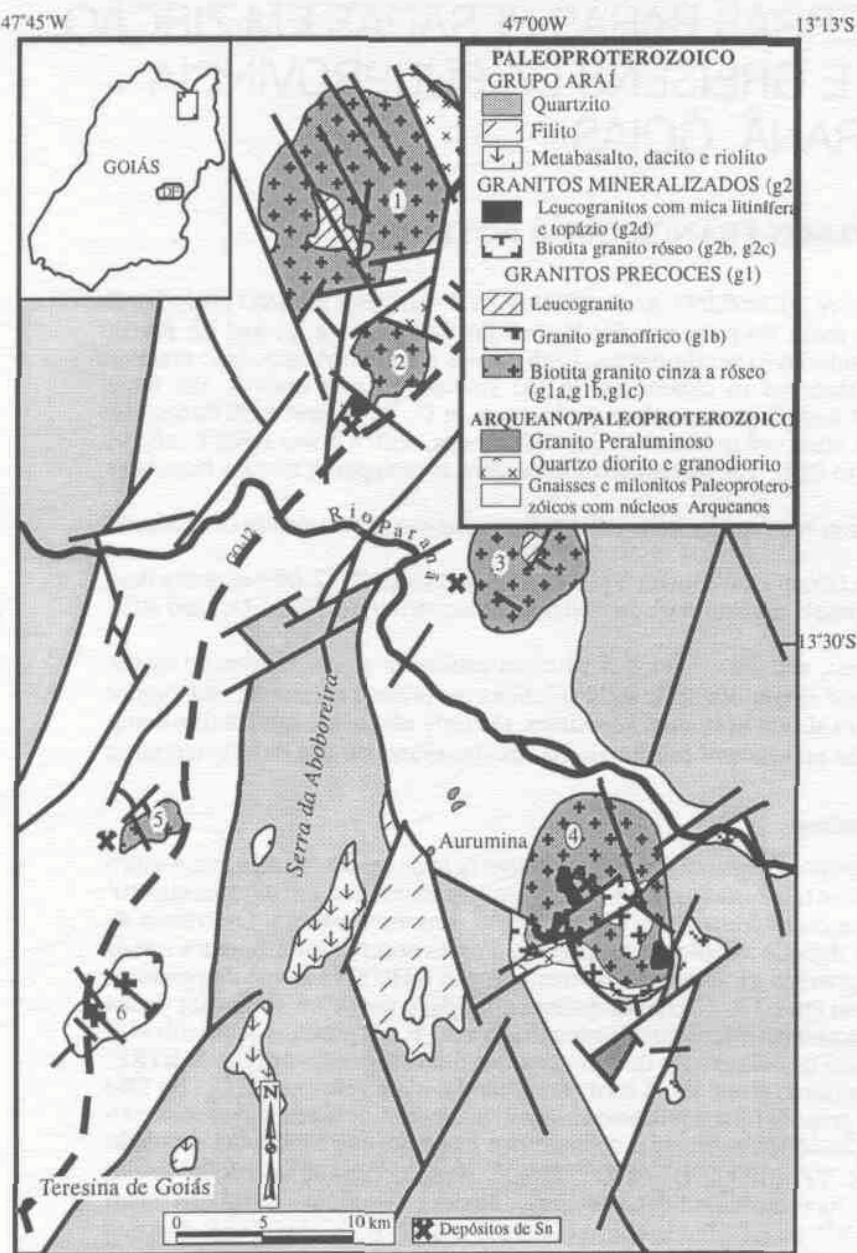

Figura 1-Mapa de localização e geológico da Subprovíncia Paranã no estado de Goiás. Maciços graníticos: I - Serra do Mendes, 2 Mangabeira, 3 - Mocambo, 4 - Pedra Branca, 5 - Sucuri, 6 Soledade.

espectro possível de rochas das suites g1 e g2 dos maciços Pedra Branca, Mocambo, Serra do Mendes e Soledade. Durante a petrografia de detalhe deu-se ênfase à identificação das fases acessórias portadoras de ETR, e às mudanças texturais nas mesmas durante a evolução magmática das suites e a atuação de processos tardi/pós magmáticos. Os minerais assim selecionados foram analisados na Microssonda Eletrônica CAMECA CAMEBAX SX-50, do Instituto de Geociências da Universidade de Brasília, equipada com um sistema de dispersão de wave length, ângulo de take off de $40^{\circ} \mathrm{e}$ aplicando o procedimento de correção PAP.

As condições de análise variaram de acordo com o elemento. Usou-se voltagem de aceleração de $20 \mathrm{KV}$, corrente de $40 \mathrm{nA}$ e tempo de contagem de 1 Os para Si, Zr, P, U, Hf e Th e $25 \mathrm{KV}$, corrente de 200nA e tempo de contagem de 20 segundos para Nb, Y e ETR. O tempo de contagem no background foi metade do medido no pico. As linhas utilizadas foram Koc para Si e P, La para Zr, Hf, Nb, La, Ce, Er e Yb; L $\beta$ para Pr, Nd, Sm, Gd e Dy e M $\alpha$ para U e Th. Apesar de as linhas utilizadas serem as que apresentam menor interferência, foram necessárias algumas correções utilizando-se os parâmetros propostos por Åmli \& Griffin (1975). Os padrões utilizados foram óxidos sintéticos de ETR, metais puros de $\mathrm{U}$, Th e $\mathrm{Nb}$, minerais naturais e óxidos sintéticos para os demais elementos. A calibração foi testada por meio da análises nos próprios padrões.

\section{CARACTERIZAÇÃO MINERALÓGICA E QUÍMICA Zircão}

$\mathrm{O}$ zircão $\left(\mathrm{ZrSiO}_{4}\right)$ é o mineral acessório mais comum nos granitos estudados, e ocorre em todas as fácies, tanto no granito inalterado quanto nos greisens.

A composição química dos cristais de zircão estudados distancia-se da do mineral ideal devido ao seu enriquecimento progressivo em $U$, Th, Y e ETR (Fig. 2 e 3 e Tabela 1). O zircão dos granitos menos
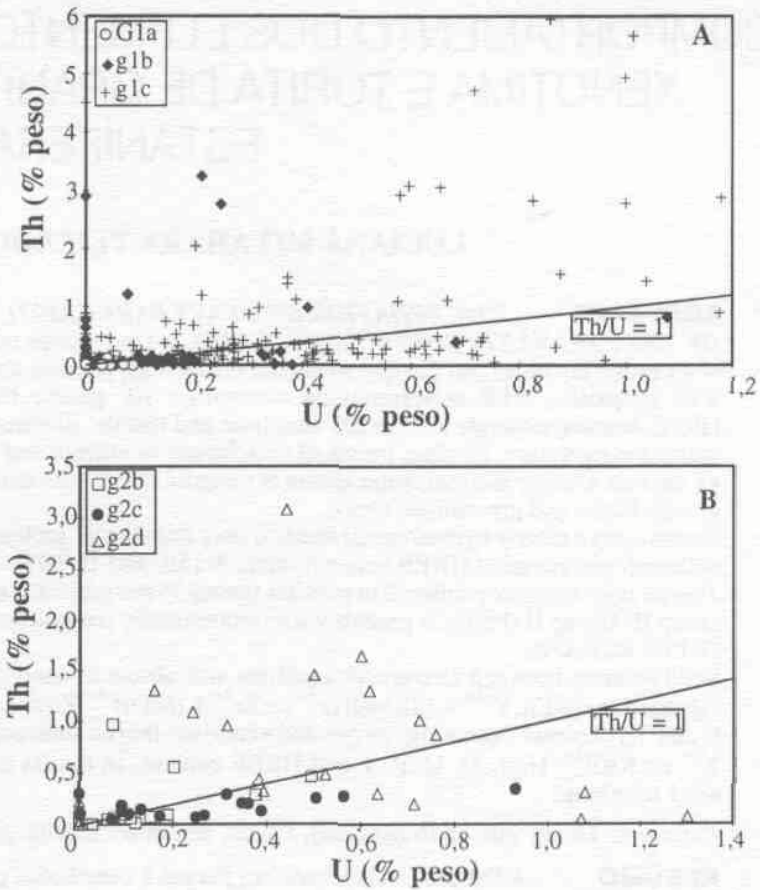

Figura 2 - Variação nos conteúdos em $U$ e Th em zircão das suites gl (A) e g2 (B).
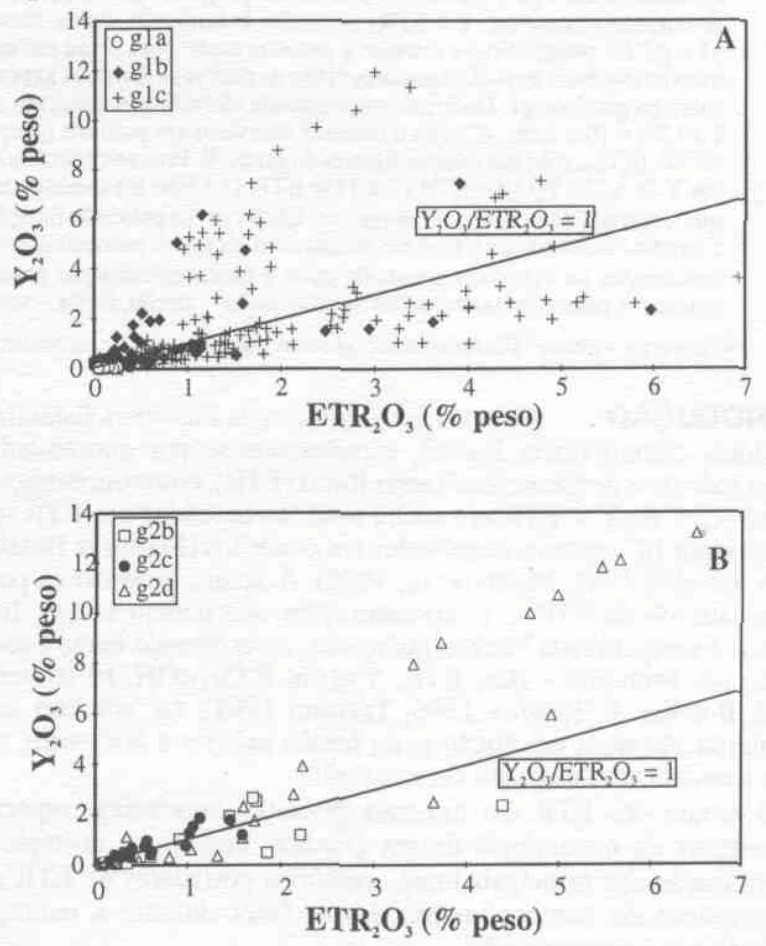

Figura 3 - Conteúdos de $\mathrm{Y}_{2} \mathrm{O}_{3}$ e $\mathrm{ETR}_{2} \mathrm{O}_{3}$ em zircão das suites gl (A) e $g 2(B)$ mostrando o enriquecimento nesses elementos com a evolução magmática.

evoluídos (gl a e g2b) apresenta apenas traços desses elementos, enquanto que o das fácies mais evoluídas ( $\mathrm{gl}$ c e g2d) apresenta conteúdo bem mais elevado nesses elementos (Tabela 1), com concentrações de até $1,4 \% \mathrm{UO}_{2} ; 6,5 \% \mathrm{ThO}_{2} ; 13 \% \mathrm{Y}_{2} \mathrm{O}_{3}$ e $7 \% \mathrm{ETR}_{2} \mathrm{O}_{3}$. Dentre os ETR, o zircão é mais enriquecido em ETRP, com concentrações em $\mathrm{Yb}_{2} \mathrm{O}_{3}$ e $\mathrm{Er}_{2} \mathrm{O}_{3}$ (os ETRP mais abundantes) de até 3\% e 2\% respectivamente (Tabela 1). Entre os ETRL, nenhum dos elementos analisados $\left(\mathrm{La}_{2} \mathrm{O}_{3}, \mathrm{Ce}_{2} \mathrm{O}_{3}, \mathrm{Pr}_{2} \mathrm{O}_{3}, \mathrm{Nd}_{2} \mathrm{O}_{3}\right.$ e $\left.\mathrm{Sm}_{2} \mathrm{O}_{3}\right)$ apresenta teores significativos. Suas concentrações variam entre $\mathrm{O}$ e $0,5 \%$ e o somatório raramente ultrapassa $1 \%$.

Zircão de rochas graníticas apresenta razão $\mathrm{Th} / \mathrm{U}<1$, com média de 0,5 (Ahrens et al 1967). Nos granitos gl e g2, a razão Th/U no 
la 1 - Dados analíticos mais representativos de zircão das suites $\mathrm{g} 1$ e $\mathrm{g} 2$.

\begin{tabular}{|c|c|c|c|c|c|c|c|c|c|c|c|c|c|c|c|c|c|}
\hline \multicolumn{3}{|c|}{ Facies 81a } & \multicolumn{6}{|c|}{ Factes gib } & \multicolumn{9}{|c|}{ F́́cies glc } \\
\hline Amostro & 1 & 2 & 3 & 4 & 5 & 6 & 7 & 8 & 9 & 10 & 11 & 12 & 13 & 14 & 15 & 16 & 17 \\
\hline $\mathrm{SiO}_{2}$ & 32,17 & 32,32 & 32.38 & 32,29 . & 30,61 & 25,66 & 26,43 & 24,74 & 29.46 & 17,87 & 22,15 & 32,10 & 17,49 & 36,42 & 25,01 & 23,89 & 18,07 \\
\hline $\mathrm{P}_{2} \mathrm{O}_{3}$ & h.d. & n.d. & n.d. & n.d. & n.d. & 1,35 & 4,11 & 5,72 & a.d. & n.d. & n.d. & n.d. & n.d. & n.d. & 1,00 & 2,08 & 1,51 \\
\hline $\mathrm{wO}_{2}$ & 0,03 & n.d. & n.d. & 0,17 & 0,13 & 0,09 & 0,11 & 0,19 & 0,31 & 1,15 & 1,34 & n.d. & 0,81 & 0.42 & 0,25 & 0.31 & 1,33 \\
\hline $\begin{array}{l}\mathrm{HrO}_{2} \\
\mathrm{ZrO}_{3}\end{array}$ & $\mid \begin{array}{l}1,4 ! \\
65,98\end{array}$ & $\begin{array}{l}1,23 \\
66,27\end{array}$ & $\begin{array}{l}0.98 \\
66,8\end{array}$ & $\begin{array}{l}1,63 \\
65,61\end{array}$ & $\begin{array}{l}2,5 \\
58,41\end{array}$ & $\begin{array}{l}1,17 \\
48,41\end{array}$ & $\begin{array}{l}2,50 \\
48.87\end{array}$ & $\begin{array}{l}2.82 \\
44.36\end{array}$ & $\begin{array}{l}1.94 \\
48.78\end{array}$ & $\begin{array}{l}1.60 \\
32.37\end{array}$ & $\begin{array}{l}2,06 \\
43,31\end{array}$ & $\begin{array}{l}1.71 \\
66.62\end{array}$ & 1,17 & 1,93 & 2,80 & 1,68 & 2.03 \\
\hline & $\begin{array}{c}53,98 \\
\text { n.d. }\end{array}$ & $\begin{array}{l}66,27 \\
\text { a.d. }\end{array}$ & {$\left[\begin{array}{l}06,8 \\
0,12\end{array}\right.$} & $\begin{array}{l}65,61 \\
0,08\end{array}$ & $\begin{array}{l}58,41 \\
0,11\end{array}$ & $\begin{array}{l}48,41 \\
1,38\end{array}$ & $\begin{array}{l}48.87 \\
0.18\end{array}$ & $\begin{array}{l}44,36 \\
0,28\end{array}$ & $\begin{array}{l}48,78 \\
0,73\end{array}$ & $\begin{array}{l}32,37 \\
6,43\end{array}$ & $\begin{array}{l}43,31 \\
3,26\end{array}$ & $\begin{array}{l}66,62 \\
0,02\end{array}$ & $\begin{array}{l}32,42 \\
536\end{array}$ & & 49,58 & 46,31 & 43,72 \\
\hline $\mid \begin{array}{l}\mathrm{ThO}_{2} \\
\mathrm{Y}_{2} \mathrm{O}_{3}\end{array}$ & 0,05 & 0,08 & 0,07 & $\begin{array}{l}0,00 \\
0,12\end{array}$ & 0.71 & 2,31 & 6,97 & $\begin{array}{l}0,20 \\
7,52\end{array}$ & $\begin{array}{l}0,13 \\
2,82\end{array}$ & $\begin{array}{l}6,43 \\
3,09\end{array}$ & $\begin{array}{l}3,26 \\
3,60\end{array}$ & $\begin{array}{l}0,02 \\
0,04\end{array}$ & $\begin{array}{l}5,36 \\
2,6\end{array}$ & $\begin{array}{r}1,70 \\
0,7\end{array}$ & 0,20 & 0.50 & 1,01 \\
\hline$\left\{\begin{array}{l}\mathrm{Y}_{2} \mathrm{O}_{3} \\
\mathrm{~L}_{2} \mathrm{O}_{3}\end{array}\right.$ & n.d. & 0,02 & n,d. & 0,03 & 0,01 & 0,09 & n.d. & n.a. & a.d. & n.a. & & $\begin{array}{l}0,04 \\
0,02\end{array}$ & $\begin{array}{l}2.6 \\
0,06\end{array}$ & 0,47 & 2,08 & 2,72 & 1,96 \\
\hline $\mathrm{La}_{2} \mathrm{O}_{3}$ & & & & & & & & & & & & 0,02 & 0,06 & 0,01 & n.d. & n.d. & 0,01 \\
\hline $\mathrm{Ce}_{2} \mathrm{O}_{3}$ & 0,02 & n.d. & n.d. & 0,01 & 0.01 & 1,99 & 0,01 & p.a. & 0.11 & n.a. & 0,27 & n.d. & 0.25 & 0,10 & 0.13 & 0,13 & 0.16 \\
\hline $\mathrm{P}_{2} \mathrm{O}_{3}$ & 0.07 & n.d. & n.d. & 0,03 & n.d. & 0,01 & 0,04 & n.a. & 0.03 & в.а. & 0,08 & n.d. & 0,12 & 0,01 & n,d. & o.d. & 0.13 \\
\hline $\mathrm{Nd}_{2} \mathrm{O}$ & n..d. & 0,02 & 0,02 & n.d. & 0,06 & 0,19 & 0,03 & th.a. & 0.11 & n.a. & 0,05 & n.d. & 0.04 & 0,04 & n.d. & n.d. & 0.08 \\
\hline $\mathrm{Sm}_{2} \mathrm{O}_{3}$ & 0,02 & 0,06 & n.d. & n.d. & 0,02 & 0.16 & 0.03 & $n, \ldots$ & 0,03 & $\mathbf{b}, \mathbf{a}$. & 0,09 & 0,03 & 0,04 & 0,08 & 0.03 & 0,06 & 0.10 \\
\hline $\mathrm{Gd}_{2} \mathrm{O}_{3}$ & n.d. & n.d. & p.d. & n.d. & 0,08 & 0.64 & 0,74 & the. & 0.32 & D.a. & 0,66 & n.d. & 0,50 & 0,11 & 0.35 & 0.41 & 0.66 \\
\hline $\mathrm{Dy}_{2} \mathrm{O}$ & n.d. & 0,04 & 0,06 & 0,04 & 0.14 & 1,09 & 1,15 & n.a. & 0,49 & n.a. & 1,05 & 0.01 & 0,84 & 0,21 & 0,51 & 0.72 & 1.06 \\
\hline $\mathrm{E}_{2} \mathrm{O}_{3}$ & 0,04 & n.d. & 0,05 & 0.07 & 0,29 & 0,89 & 1,74 & 1,93 & 0,97 & 1,36 & 1,56 & n.d. & $t, 28$ & 0.31 & 1,03 & 1.06 & 1,09 \\
\hline $\mathrm{yb}_{2} \mathrm{O}_{3}$ & 0.01 & 0,11 & a.d. & 0,11 & 0,44 & 0,91 & 2,62 & 2.84 & 3,18 & 2.62 & 3.16 & 0,04 & 1,99 & 0,46 & 2,52 & 2,46 & 1,62 \\
\hline TOTAL & $99, \pi 1$ & 100,15 & 100,48 & 100,19 & 93,54 & 86,33 & 95,55 & 9,4 & 89,28 & $6,4,48$ & 8265 & 100,60 & 65,03 & 87,42 & 85,47 & 82,32 & 74,54 \\
\hline \multicolumn{18}{|c|}{ Concentraço Atómica } \\
\hline Si & 0,535 & 0,538 & 0.539 & 0,537 & 0,509 & 0,427 & 0,440 & $\overline{0,412}$ & 0.490 & 0,297 & 0,369 & 0,534 & 0,291 & 0,440 & 0,416 & 0,398 & 0,301 \\
\hline . & & & & & & 0,01 & 0,029 & 0,040 & & & & & & & 0,007 & 0,015 & 0,011 \\
\hline $\mathbf{u}$ & & & & 0,001 & & 0 & 0 & 0,001 & 0,001 & 0,004 & 0,005 & 0 & 0,003 & 0,002 & 0,001 & 0,001 & 0,005 \\
\hline Hf & 0.007 & 0,006 & 0,005 & 0,008 & 0,012 & 0,006 & 0,012 & 0,01 & 0,009 & 0,008 & 0,010 & 0,008 & 0.006 & 0,009 & 0,013 & 0,008 & 0,010 \\
\hline $\mathrm{zr}$ & 0.535 & 0.538 & 0,542 & 0,532 & 0,474 & 0,393 & 0,397 & 0,360 & 0,396 & 0,263 & 0.351 & 0.541 & 0,263 & 0,448 & 0,402 & 0,376 & 0,355 \\
\hline Th & 0 & & & & & 0,005 & 0,001 & 0,001 & 0.003 & 0,024 & 0,012 & 0 & 0,020 & 0,006 & 0,001 & 0,002 & 0,004 \\
\hline$Y$ & 0 & 0,001 & 0.001 & 0,001 & 0,006 & 0,020 & 0,062 & 0,067 & 0,025 & 0,027 & 0,032 & 0 & 0,023 & 0,004 & 0.018 & 0,024 & 0,017 \\
\hline Gd & 0 & & 10 & 0 & & 0,004 & 0,004 & 0 & 0.002 & 0 & 0,004 & 0 & 0.003 & 0,001 & 0,002 & 0,002 & 0,004 \\
\hline Dy & 0 & 0 & 0 & 0 & 0,001 & 0,006 & 0,006 & & 0,003 & & 0,006 & 0 & 0,005 & 0.001 & 0.003 & 0,004 & 0.006 \\
\hline Er & 0 & 0 & 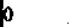 & 0 & 0.002 & 0,005 & 0,009 & 0,010 & 0.005 & 0,007 & 0,008 & 0 & 0,007 & 0.002 & 0,005 & 0.006 & 0.006 \\
\hline$y b$ & 6 & 0,001 & 0 & 0,00 & 0,002 & 0,005 & 0.013 & 0,014 & 0.016 & 0,013 & 0,016 & 0 & 0,010 & 0,002 & 0,013 & 0,012 & 0.008 \\
\hline
\end{tabular}

\begin{tabular}{|c|c|c|c|c|c|c|c|c|c|c|c|c|c|c|c|c|c|c|c|}
\hline \multicolumn{6}{|c|}{ Fácies 82b } & \multicolumn{5}{|c|}{ Fícies q2c } & \multicolumn{9}{|c|}{ Fácies gd } \\
\hline Amoetra & 18 & 19 & 20 & 21 & 22 & 23 & 24 & 23 & 26 & 27 & 28 & 20 & 30 & 31 & 32 & 33 & 34 & 35 & 36 \\
\hline $\begin{array}{l}\mathrm{SiO}_{2} \\
\mathrm{P}_{2} \mathrm{O}_{3}\end{array}$ & $\begin{array}{l}32,29 \\
\text { n.d. }\end{array}$ & $\begin{array}{l}32,27 \\
\text { n.d. }\end{array}$ & $\begin{array}{l}28,79 \\
\text { n.d. }\end{array}$ & $\begin{array}{l}27,02 \\
\text { n.d. }\end{array}$ & $\begin{array}{l}26,75 \\
7,72\end{array}$ & $\begin{array}{l}29.12 \\
\text { n.d. }\end{array}$ & $\begin{array}{l}25,25 \\
\text { n.d. }\end{array}$ & $\begin{array}{l}31,37 \\
\text { n.d. }\end{array}$ & $\begin{array}{l}31,33 \\
\text { a.d. }\end{array}$ & $\begin{array}{l}28,90 \\
\text { n.d. }\end{array}$ & $\begin{array}{l}31,82 \\
\text { 1.d.d. }\end{array}$ & $\begin{array}{l}26,99 \\
0,32\end{array}$ & $\begin{array}{l}23,48 \\
0,69\end{array}$ & $\begin{array}{l}20,72 \\
0,72\end{array}$ & $\begin{array}{l}24,87 \\
0.75\end{array}$ & $\begin{array}{l}27.09 \\
0.59\end{array}$ & $\begin{array}{l}31,55 \\
\text { n.d. }\end{array}$ & $\begin{array}{l}30,30 \\
\text { n.d. }\end{array}$ & $\begin{array}{l}29,67 \\
\text { a.d. }\end{array}$ \\
\hline $\mathrm{UO}_{2}$ & n.d. & n.d. & 0,43 & 0,08 & 0,03 & 0,39 & 0,64 & 0,10 & n,d, & 0.57 & B.d. & n.d. & 0,27 & 0,36 & 0.18 & 0,70 & 0.11 & 1,23 & 0,45 \\
\hline $\mathrm{H}_{\mathrm{HO}}$ & 1,17 & 1.73 & 1,27 & 0.84 & 1,03 & 2.11 & 1.85 & 2,08 & 2,04 & 1,89 & 1,46 & 2,23 & 2,96 & 2,28 & 2,59 & 2,00 & 1,63 & 5,05 & 2,14 \\
\hline $\mathrm{ZO}_{2}$ & 66,55 & & 52.25 & 40,05 & 44,97 & 55,32 & 49,42 & 61,50 & 62,34 & 54,14 & 64,19 & 51,69 & 36,27 & 30,00 & 35,17 & 32.61 & 63,22 & 36.31 & 54,95 \\
\hline $\mathrm{ThO}_{2}$ & 0,07 & ด.d. & 0,32 & 1,11 & n.d. & 0,23 & 0,32 & 0,21 & 0.12 & 0,29 & 0,17 & 0,26 & 1,24 & 1.09 & 1,49 & I.48 & 0.11 & 0.35 & 0,37 \\
\hline $\mathrm{Y}_{2} \mathrm{O}_{3}$ & 0,10 & 0,01 & 1,17 & 2,31 & 0,49 & 0.56 & 1,13 & 0,40 & 1,46 & 0.21 & 1,13 & 3,90 & 11,80 & 9,97 & 12,10 & 3,62 & 0,17 & 0,36 & 0,32 \\
\hline $\mathrm{L} \mathrm{r}_{2} \mathrm{O}$, & 0.04 & 0,02 & 0.06 & 0,47 & 0.40 & h.d. & o.d. & n.d. & n.d. & 0,01 & 0,01 & a,d. & 0.03 & 0,01 & n.d. & n.d. & 0,02 & n,d. & n.d. \\
\hline $\mathrm{Ce}_{2} \mathrm{O}_{3}$ & 0,01 & n.d. & 0,26 & 0,88 & 0.22 & 0,04 & 0,03 & 0,02 & n,d. & 0,02 & p.d. & 0,02 & 0,06 & 0,12 & 0,04 & 0,34 & 0,02 & 0,01 & n.d. \\
\hline $\mathrm{Pr}_{2} \mathrm{O}_{3}$ & n.d. & n.d. & 0,02 & 0,15 & 0.13 & 0,03 & 0,05 & n.d. & n,d. & 0,02 & h.d. & 0,02 & n.d. & n.d. & 0.01 & n.d. & 0,03 & p.d. & n.d. \\
\hline $\mathrm{Ndd}_{2} \mathrm{O}_{3}$ & 0,07 & n,d. & 0,20 & 0,34 & 0,40 & 0,09 & 0,01 & n.d. & n.d. & n.d. & 0,02 & n.d. & 0,09 & 0,05 & 0,01 & 0,03 & 0.05 & 0.05 & 0,02 \\
\hline $\mathrm{Sm}_{2} \mathrm{O}_{3}$ & a.d. & n,d. & 0,09 & 0,08 & 0,10 & and.d. & 0,02 & n.d. & n.d. & 0.04 & h.d. & 0,03 & 0,05 & 0.06 & 0,07 & 0,12 & 0.02 & 0.03 & 0.04 \\
\hline $\mathrm{Gd}_{2} \mathrm{O}_{3}$ & a.d. & 0,04 & 0,25 & 0.43 & 0.20 & 9,06 & 0.11 & 0,06 & n.d. & n.d. & b.02 & 0,27 & 0,60 & 0,54 & 0,69 & 0,38 & 0,05 & 0,17 & 0,10 \\
\hline $\mathrm{Dy}_{2} \mathrm{O}_{3}$ & 0,05 & n.d. & 0,37 & 0,45 & 0.12 & 9,10 & 0.19 & 0,06 & n.d. & n.d. & 0.04 & 0.46 & $0 . \% 6$ & 0,87 & 0,95 & 0,901 & It.d. & 0.13 & 0.08 \\
\hline $\mathrm{Er}_{2} \mathrm{O}$ & 0,03 & n.d. & 0,40 & 0.64 & 0,13 & 0.21 & 0,38 & 0.16 & 0.40 & 0.II & 0.12 & 0,63 & 1.57 & 1.31 & 1.62 & 1.27 & 0.12 & 0.29 & 0.15 \\
\hline $\mathrm{Y}_{\mathrm{b}_{2}} \mathrm{O}_{3}$ & 0,02 & 0,02 & 0,56 & 0,94 & 0,16 & 0.43 & 1.05 & 0,38 & 0.73 & 0,19 & 0,15 & 0,80 & 2,09 & 1,71 & 2.29 & 2.50 & 0,16 & 0,63 & 0,42 \\
\hline TOTAL & 100,42 & 100,86 & 86,44 & 75,80 & 82,84 & 38,68 & 80,16 & 96,33 & 9,06 & 8640 & 199,10 & 87,62 & 82,59 & 69,80 & 82,80 & 73,62 & 97,26 & $94,9 !$ & 88,68 \\
\hline \multicolumn{20}{|c|}{ Concentraça Atomica } \\
\hline $\mathbf{S i}$ & 0,537 & 0.537 & 0,479 & 0.450 & 0,445 & 0,485 & $0, \overline{420}$ & 0,522 & 0,521 & 0,481 & 0,530 & 0,449 & 0,391 & 0,345 & 0,414 & 0.451 & 0,525 & 0,504 & 0,494 \\
\hline & & 0 & & & 0,054 & & & 0 & 0 & 0 & & 0,002 & 0,005 & 0,005 & 0,005 & 0.004 & 0 & & \\
\hline $\mathrm{u}$ & & 0 & 0.002 & 0 & 0 & 0,001 & 0,002 & 0 & 0 & 0,002 & & 0 & 0,001 & 0.001 & 0,001 & 0.003 & 0 & 0,005 & 0,002 \\
\hline HF & 0.006 & 0,008 & 0.006 & 0,004 & 0,005 & 0,010 & 0,009 & 0,010 & 0,010 & 0.009 & 0,007 & 0,011 & 0,014 & 0,011 & 0.012 & 0,010 & 0,008 & 0,024 & 0,010 \\
\hline $\mathrm{Zr}$ & 0,540 & 0,542 & 0,424 & 0,325 & 0.365 & 0,449 & 0,401 & 0.499 & 0,506 & 0,439 & 0,521 & 0.419 & 0.294 & 0.243 & 0,285 & 0.265 & 0,513 & 0,457 & 0.446 \\
\hline Th & 0 & 0 & 0,001 & 0,004 & 0 & 0,001 & 0,001 & 0,001 & 0 & 0.001 & 0,001 & 0,001 & 0,005 & 0,004 & 0,006 & 0,006 & 0 & 0,001 & 0.001 \\
\hline $\mathbf{Y}$ & 0,001 & 0 & 0.010 & 0,020 & 0,004 & 0,005 & 0,010 & 0,004 & 0,013 & 0,002 & b,010 & 0,035 & 0,105 & 0.088 & 0.107 & 0,032 & 0,002 & 0,003 & 0,003 \\
\hline Gd & b & 0 & 0.001 & 0,002 & 0,001 & & 0,001 & 0 & 0.001 & 0 & & 0.002 & 0,003 & 0,003 & 0,004 & 0,002 & 0 & 0,001 & 0.001 \\
\hline Dy & 0 & 0 & 0,002 & 0,002 & 0,001 & 0,001 & 0,001 & 0 & 0,002 & 0 & & 0,002 & 0,005 & 0,005 & 0,005 & 0,005 & 0 & 0.001 & \\
\hline Er & b & 0 & 0,002 & 0,003 & 0,001 & 0,001 & 0,002 & 0,001 & 0,002 & 0,001 & 0,001 & 0,003 & 0,008 & 0,007 & 0,008 & 0,007 & 0,001 & 0,001 & 0,001 \\
\hline Yo & D & 0 & 0,003 & 0,005 & 0,001 & 0,002 & 0.005 & 0,002 & 0,004 & 0,001 & 0,001 & 0,004 & 0,011 & 0,009 & 0.012 & 0.013 & 0,001 & 0,003 & 0,002 \\
\hline
\end{tabular}

zircão varia entre $<1$ até próximo de 10 , geralmente nas fácies mais evoluídas (Fig. 2), o que não se explica unicamente pela diferença de comportamento isotópico entre U e Th. Na sua forma hexavalente, U pode ser mobilizado dos seus sítios originais e transportado na forma de carbonatos, fluoretos e fosfates (McLennan e Taylor 1979, Kamineni 1986, Cathelineau 1987), enquanto Th é considerado como um elemento pouco móvel. Durante a greisenização e a metamictização, $\mathrm{U}$ do zircão deve ter sido lixiviado dos seus sítios originais, aumentando a sua razão $\mathrm{Th} / \mathrm{U}$.

$\mathrm{O}$ zircão da suite gl se distingue do mineral da suite g2 pelos teores em $\mathrm{Y}_{2} \mathrm{O}_{3}$ e $\mathrm{ETR}_{2} \mathrm{O}_{3}$. Na suite gl observam-se dois trenas, um com razão $\mathrm{Y}_{2} \mathrm{O} 3 / \mathrm{ETR}_{2} \mathrm{O} 3>1$ e outro com esta razão $<1$ (Fig. 3a). Na suite g2 o zircão tende a apresentar razão $\mathrm{Y}_{2} \mathrm{O} 3 / \mathrm{ETR}_{2} \mathrm{O}_{3}>1$ (Fig. 3b).

Os padrões de ETR normalizados ao condrito (fatores de normalização SUN do programa NEWPET) de zircão das suites gl e g2 são semelhantes entre si. Em ambos casos, as curvas são ascendentes com razão $(\mathrm{La} / \mathrm{Yb})_{\mathrm{N}}$ sempre inferior a 0,5 e apresentam anomalias negativas em Nd. Não foram constatadas variacões significativas nas formas dos padrões de zircão de uma mesma fácies (Fig. 4a e b). Os padrões do zircão da suite g2 são semelhantes, caracterizados por uma grande variação nas concentrações dos ETRL, fato para o qual ainda não há uma explicação (Fig. 4b). Os padrões normalizados ao condrito do zircão de ambas suites são anómalos em relação aos padrões encontrados na literatura (Heaman et al. 1990), diferindo na anomalia negativas em Nd e no padrão anómalo na região dos ETRL (g2).

Xenotima A xenotima (YPO-O é claramente hidrotermal, pois ocorre exclusivamente nos greisens desenvolvidos sobre a fácies glb dos Macicos Pedra Branca e Mocambo. Relativamente aos seus conteúdos em ETRP, a xenotima divide-se em dois grupos (Fig. 5), onde o grupo I apresenta teores em ETRPiOs entre 16 e $18 \%$ e o grupo II. entre 8 e $13 \%$.

Exceto o $\mathrm{Gd}$, os demais ETRP ocorrem em concentraç̃es, em geral, entre 4 e $5 \%$ no grupo I e entre 2,5 e 3,5\% no grupo II (Tabela 2 ). Os conteúdos em ETRL são muito baixos, com somatório sempre inferior a $1 \%$ (Fig. 5). $\mathrm{La}_{2} \mathrm{O}_{3}, \mathrm{Ce}_{2} \mathrm{O}_{3} \mathrm{e} \mathrm{Pr}_{2} \mathrm{O}_{3}$ apresentam conteúdos inferiores a $0,1 \%$, e $\mathrm{Nd}_{2} \mathrm{O}_{3}$ e $\mathrm{Sm}_{2} \mathrm{O}_{3}$ atingem concentrações de até $0,5 \%$ (tabela 2).

A xenotima do grupo I apresenta teores de ETRP muito semelhantes aos observados em xenotima do pegmatito Gloserheia, Noruega (Åmli 1975), e em xenotima de pegmatitos e fissuras dos Alpes (Demartin et al. 1991). A xenotima do grupo II apresenta conteúdos de ETRP inferiores ao observado na literatura. Em ambos grupos, as variações do ETRL são semelhantes às observadas por Åmli (1975) e Franz et al. (1996) (Fig. 5).

Os padrões de ETR normalizados ao condrito da xenotima de ambos grupos são fortemente ascendentes do $\mathrm{La}$ ao $\mathrm{Gd}$ tornando-se aproximadamente planos na região dos ETRP (Fig. 6). Diferem na anomalia positiva em Pr observada na xenotima do grupo I e no leve enriquecimento em ETRP apresentado por este grupo em relação ao grupo II. Esses padrões de ETR são muito semelhantes aos obtidos por Franz et al. (1996) em xenotima metamórfica da Bavária (Alemanha). Diferem apenas na anomalia positiva em Pr constatada na xenotima do grupo I. 
Torita A torita $\left(\mathrm{ThSiO}_{4}\right)$ foi encontrada nas fácies mais evoluídas de ambas as suites (glc e g2d), embora seja mais comum nos granitos gl. Encontra-se em um avançado estado de metamictização, o que provoca a diminuição do seu relevo e cor de interferência.

Textural e quimicamente foi possível individualizar dois grupos de torita (Fig. 7), onde o grupo I é representado pela torita de granitos inalterados, cujos conteúdos em $\mathrm{Y}_{2} \mathrm{O}_{3}$ e $\mathrm{ETR}_{2} \mathrm{O}_{3}$ variam de $1 \%$ a $5 \%$ e $2 \%$ a $6 \%$ respectivamente, e o grupo II que ocorre em granitos greisenizados e greisens, com conteúdos em $\mathrm{Y}_{2} \mathrm{O}_{3}$ e $\mathrm{ETR}_{2} \mathrm{O}_{3}$ mais elevados que no grupo I (4 - 7\% e $7-13 \%$ respectivamente) (Tabela 3).

Em ambos grupos, os ETRL tendem a ocorrer em concentrações inferiores a $0,5 \%$. Dentre os ETRP, a torita é mais rica em $\mathrm{Yb}_{2} \mathrm{O}_{3}$ (até $5 \%$, seguido por $\mathrm{Er}_{2} \mathrm{O}_{3}, \mathrm{Dy}_{2} \mathrm{O}_{3}$ e $\mathrm{Gd}_{2} \mathrm{O}_{3}$, em ordem decrescente (Tabela 3).

A torita do grupo I é mais pobre em $\mathrm{Y}_{2} \mathrm{O}_{3}$ e $\mathrm{ETR}_{2} \mathrm{O}_{3}$ que a do pegmatito granítico de Seerie, Colorado (Staatz et al. 1976), enquanto que a do grupo II apresenta composição semelhante à daquele pegmatito (Fig. 7). A torita encontrada no pegmatito com tendência alcalina de Harding, Novo México (Lumpkin \& Chakoumakos 1988) é muito pobre em $\mathrm{Y}_{2} \mathrm{O}_{3}$ e $\mathrm{ETR}_{2} \mathrm{O}_{3}$, com concentrações inferiores à da torita do grupo I (Fig. 7).

A torita estudada possui $\mathrm{P}_{2} \mathrm{O}_{5}, \mathrm{ZrO}_{2}$ e $\mathrm{UO}_{2}$ em concentrações de até 4,10 e $12,5 \%$, respectivamente (Tabela 3 ). A torita com os mais altos conteúdos $\mathrm{em} \mathrm{UO}_{2}$ foi encontrada em rochas que não apresentam evidências de alteração hidrotermal supondo-se, portanto, que o mineral não sofreu mudanças na sua composição química em decorrência da greisenização. Assim, é provável que a torita original dos granitos estudados era rica em $\mathrm{UO}_{2}$.

Os padrões de ETR da torita dos grupos I e II, normalizados ao condrito, são contrastantes (Fig. 8). A torita do grupo I é mais rica em ETRL e mais pobre em ETRP, com distribuição plana $\left.(\mathrm{La} / \mathrm{Gd})_{\mathrm{N}}=0,2\right)$,
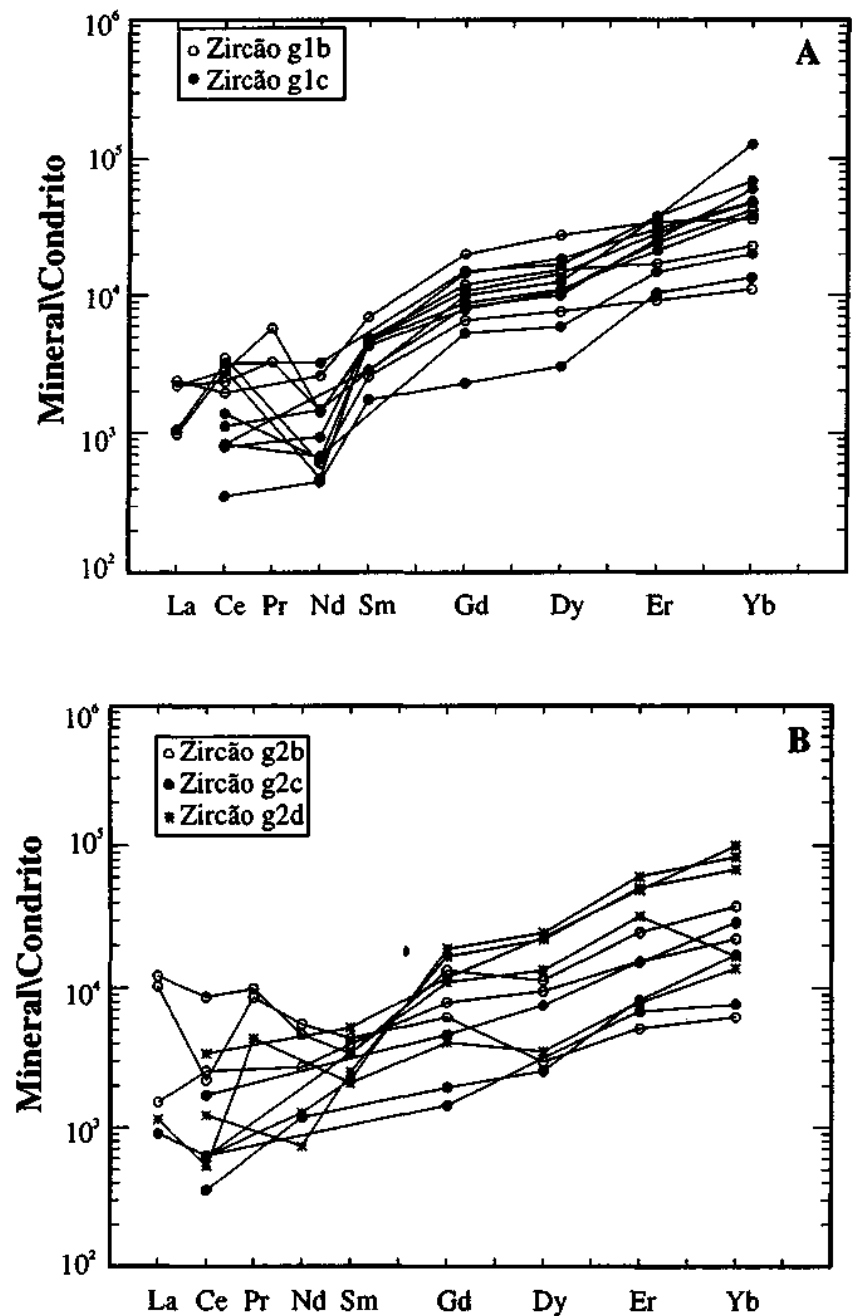

Figura 4 - Padröes de ETR normalizados a condrito de zircão das suites $g 1(A)$ e g2 $(B)$. comparativamente à do grupo II, mais pobre em ETRL e mais rica em ETRP, com aumento gradual do $\mathrm{Nd}$ ao $\mathrm{Yb}\left((\mathrm{La} / \mathrm{Gd})_{\mathrm{N}}=0,06-0,08\right)$.

CRISTALOQUÍMICA E SOLUÇÕES SÓLIDAS O zircão é um mineral tetragonal com grupo I4i/amd. O mineral apresenta dois sítios principais na sua estrutura, cuja fórmula geral pode ser escrita como $\mathrm{ABO}_{4}$ : sítio $\mathrm{A}=\mathrm{Zr}$, Hf, Y, ETR, U, Th e Fe e sítio $\mathrm{B}=\mathrm{Si}, \mathrm{P}$, OH (Mumpton \& Roy 1961, Speer 1982). A xenotima e a torita são isoestruturais com o zircão.

Zircão Os dados analíticos de zircão foram dispostos em uma diagrama ZR x SI $(\mathrm{ZR}=$ concentração atómica de $\mathrm{Zr}+\mathrm{Hf}+\mathrm{U}+\mathrm{Y}+$ ETR; SI = concentração atômica de $\mathrm{Si}+\mathrm{P}$ ) (Fig. 9). No diagrama, os dados localizam-se preferencialmente ao longo de uma linha $\mathrm{ZR} / \mathrm{SI}=$ 1, mostrando que as análises estão completas, mesmo apresentando baixos totais, pois a razão descrita acima aproxima-se da observada em zircão normal $(\mathrm{Zr} / \mathrm{Si}=1)$. Os pontos que se afastam muito da linha, principalmente das fácies glc e g2d, resultam de cristais metamícticos ricos em água.

Os baixos totais observados em algumas análises (Tabela 1) e a ausência de elementos não analisados (Fig. 9) indicam a existência de elevados conteúdos de água no zircão. $\mathrm{O}$ conteúdo de $\mathrm{H}_{2} \mathrm{O}$ foi calculado por diferença de $100 \%$ e os dados dispostos no diagrama $\mathrm{ZrO}_{2}$ $\mathrm{SiO}_{2}-\mathrm{H}_{2} \mathrm{O}$ em base molecular (Mumpton \& Roy 1961) (Fig. 10). Ainda que se observe uma dispersão dos dados, as análises dispõ̃em-se preferencialmente ao longo da linha $\mathrm{ZrSiO}_{4}-\mathrm{H}_{2} \mathrm{O}$, indicando que, na estrutura do zircão, a água ocorre essencialmente na forma molecular.

Espectros de Infravermelho obtidos em amostras de zircão das fácies mais evoluídas (glc e g2d) apresentam uma forte absorção na região de $3455 \mathrm{~cm}_{-}^{1}$, interpretada como decorrente da presença de água como $\mathrm{H}_{2} \mathrm{O}$ (Marel \& Beutelspacher 1976). Uma pequena absorção a $1630 \mathrm{~cm}^{1}$ foi interpretada como devido à presença de $\mathrm{OH}$, ainda que em pequenas quantidades, confirmando observações anteriores.

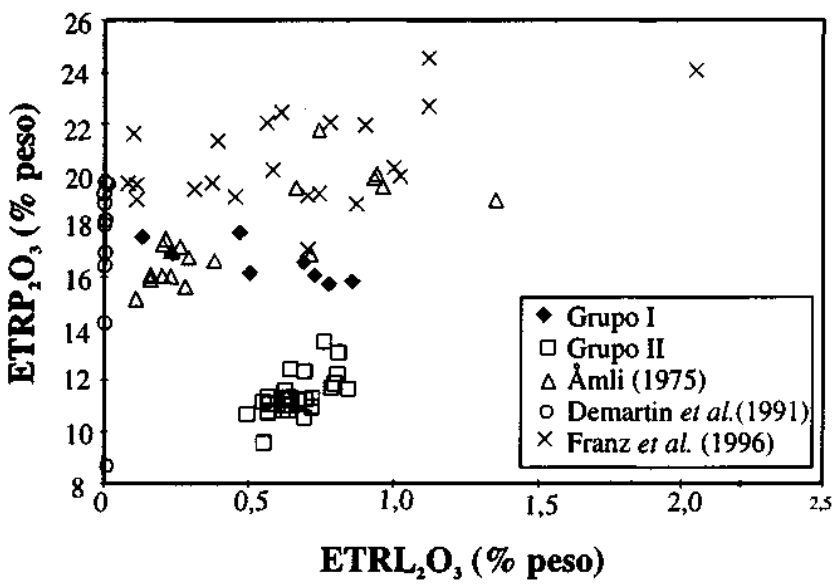

Figura 5 - Variação nos conteúdos de ETRP e ETRL na xenotima analisada e comparaçâo com dados da literatura.

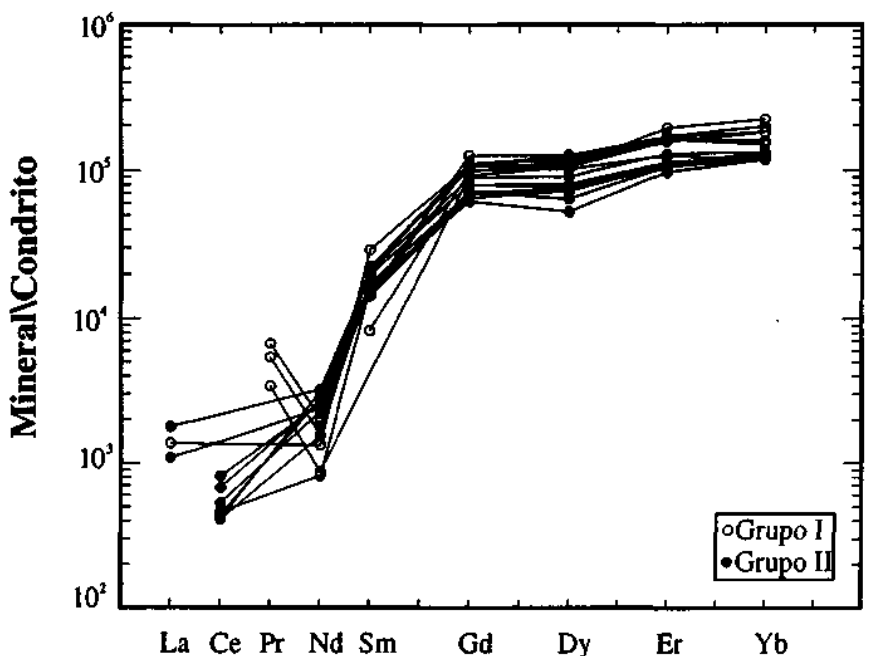

Figura 6 - Padröes de ETR normalizados ao condrito de tenotima dos grupos I e II. 
Tabela 2 - Dados analíticos mais representativos de xenotima dos grupos Ie ll. A fómula estrutural foi calculada com base em quatro oxigênios.

\begin{tabular}{|c|c|c|c|c|c|c|c|c|c|c|c|c|c|c|c|c|c|c|c|}
\hline \multicolumn{7}{|l|}{ Grupe I } & \multicolumn{13}{|c|}{ Grupo II } \\
\hline Amostra & 1 & 2 & 3 & 4 & 5 & 6 & 7 & 8 & 9 & 10 & 11 & 12 & 13 & 14 & 15 & 16 & 17 & 18 & 19 \\
\hline $\begin{array}{l}\mathrm{SiO}_{2} \\
\mathrm{P}, \mathrm{O}_{6}\end{array}$ & $\begin{array}{l}4,45 \\
32,65\end{array}$ & $\begin{array}{l}0,30 \\
36,01\end{array}$ & $\begin{array}{l}0,08 \\
36.16\end{array}$ & $\begin{array}{l}\text { n.d. } \\
35.59\end{array}$ & $\begin{array}{l}0,17 \\
33,97\end{array}$ & $\begin{array}{l}\text { n.d. } \\
36.33\end{array}$ & $\begin{array}{l}\text { m.d. } \\
38.04\end{array}$ & $\begin{array}{l}\text { a.d. } \\
36.14\end{array}$ & n.d. & $\begin{array}{l}m . d_{t} \\
38.29\end{array}$ & $\begin{array}{l}\text { n.d. } \\
38.22\end{array}$ & n.d. & $\begin{array}{l}0,22 \\
34,84\end{array}$ & $\begin{array}{l}2,51 \\
32,79\end{array}$ & n.d. & $\begin{array}{l}0,60 \\
347\end{array}$ & $\begin{array}{l}\text { n.d. } \\
3703\end{array}$ & n.d. & 0,27 \\
\hline $\begin{array}{l}\mathrm{P}_{2} \mathrm{O}_{5} \\
\mathrm{ThO}_{7}\end{array}$ & 0 & $\begin{array}{l}30,01 \\
0.22\end{array}$ & $\begin{array}{l}0,24 \\
0 ., 10\end{array}$ & 0,26 & 0.07 & $\begin{array}{l}\text { n.d. } \\
\text { n.p. }\end{array}$ & $\begin{array}{l}0,04 \\
0,07\end{array}$ & $\begin{array}{l}30,14 \\
\text { n.d. }\end{array}$ & nid. & $\begin{array}{l}30,29 \\
0,11\end{array}$ & $\begin{array}{l}36,22 \\
0,10\end{array}$ & $\begin{array}{l}3 /, 91 \\
0,13\end{array}$ & $\begin{array}{l}34,84 \\
0,22\end{array}$ & $\begin{array}{l}32,79 \\
0,33\end{array}$ & $\begin{array}{l}38,44 \\
0,05\end{array}$ & $\begin{array}{l}34,7 n \\
0,06\end{array}$ & $\begin{array}{l}37,03 \\
\text { n.d. }\end{array}$ & $\begin{array}{l}37,82 \\
\text { n.d. }\end{array}$ & $\begin{array}{l}36,90 \\
0,20\end{array}$ \\
\hline $\mathrm{Nb}_{2} \mathrm{O}_{\mathrm{t}}$ & h.d. & n.d. & n.d. & 0,14 & 0,22 & 0,12 & 0,05 & n,d. & 0,05 & 0,05 & 0.01 & 0,07 & n.d. & 0,22 & 0,06 & 0,16 & 0.11 & n.d. & 0,11 \\
\hline $\mathrm{Y}_{2} \mathrm{O}_{3}$ & 45,93 & 45,13 & 45,63 & 46,09 & 44,35 & 43,71 & 48,23 & 48.57 & 48,87 & $48,9 \mathrm{~J}$ & 48,74 & 50,89 & 41,38 & 46,18 & 50.14 & 41,79 & 46.74 & 50,11 & 45,98 \\
\hline $\mathrm{La}_{2} \mathrm{O}_{3}$ & n.d. & m.d. & h.d. & n.d. & 0.01 & 0,05 & n.d. & 0,01 & n.d. & n.d. & n.d. & 0,02 & 0,01 & 0,01 & n.d. & n.d. & 0,04 & 0,07 & n.d. \\
\hline $\mathrm{Ce}_{2} \mathrm{O}_{3}$ & 0,05 & 0,01 & n.d. & n.d. & n.d. & 0,02 & 0,05 & 0,05 & n.d. & 0,05 & 0,10 & 0,04 & 0,07 & 0,04 & 0,03 & n.d. & 0.02 & 0,02 & 0,04 \\
\hline $\mathrm{PT}_{2} \mathrm{O}_{3}$ & n.d. & n.d. & 0,04 & 0,08 & n.d. & n.d. & n.d. & 0,09 & 0,08 & 0,03 & n.d. & n.d. & n.d. & 0,01 & n.d. & 0,13 & n.d. & n.d. & n.d. \\
\hline $\mathrm{Nd}_{2} \mathrm{O}_{3}$ & 0.06 & 0.15 & n.d. & 0,12 & 0.16 & 0,10 & 0,25 & 0,17 & 0,13 & 0,21 & 0,19 & 0,23 & 0,20 & 0,18 & 0,15 & 0,20 & 0,18 & 0,24 & 0,11 \\
\hline $\mathrm{Sm}_{2} \mathrm{O}_{3}$ & 0,36 & 0,35 & 0,20 & 0,53 & 0,52 & 0,69 & $0,5 t$ & 0,53 & 0,41 & 0,41 & 0,36 & 0,35 & 0,34 & 0,39 & 0,38 & 0,49 & 0,52 & 0,46 & 0,40 \\
\hline $\mathrm{Gd}_{7} \mathrm{O}_{3}$ & 3.90 & 3,46 & 3,13 & 3.55 & 3,51 & 3,48 & 2.75 & 2,52 & 2,48 & 2,29 & 2,31 & 2,30 & 2,07 & 2,20 & 2,14 & 2,84 & 3.21 & 2,55 & 1,97 \\
\hline$D y_{2} \mathrm{O}_{3}$ & 4,96 & 4,12 & 4,42 & 4,59 & 4,86 & 4,25 & 3.36 & 3,07 & 2,75 & 2,54 & 3,01 & 2.87 & 2,86 & 2,71 & 2,60 & 3,57 & 4,02 & 3,18 & 2,08 \\
\hline $\mathrm{Er}_{2} \mathrm{O}_{3}$ & 4,32 & 4,04 & 4,38 & 4,14 & 4,22 & 4,15 & 2,94 & 2,94 & 2,72 & 2,71 & 2,80 & 2,84 & 2.75 & 2,73 & 2.77 & 3.32 & 3,24 & 2.91 & 2,52 \\
\hline $\mathrm{Yb}_{2} \mathrm{O}_{3}$ & 5,54 & 4,54 & 4,95 & 3.74 & 3,97 & 3,88 & 3,12 & 3,08 & 3,03 & 3,00 & 3.16 & 3,20 & 3,13 & 3.17 & 3,26 & 3,34 & 2,97 & 3,02 & 2,98 \\
\hline TOTAL & 101,62 & 98,33 & 99,23 & 98,83 & 96,03 & 96,71 & 99,37 & 97,17 & 98,55 & 98,69 & 99,00 & 100,85 & 88,09 & 93,47 & 100,03 & 91,21 & 98,08 & 100,38 & 93,56 \\
\hline \multicolumn{20}{|c|}{ Fórmula Estrutural Calculada com Base em Quatro Oxigênios } \\
\hline Si & 0,144 & 0.010 & 0,003 & 0 & 0,006 & 0 & 0 & $\overline{0}$ & 0 & 0 & 0 & 0 & 0,008 & 0,086 & 0 & 0,021 & 0 & 0 & 0,009 \\
\hline & 0,895 & 1,009 & 1,009 & $1,00 \mathrm{l}$ & 0,990 & 1,026 & 1,028 & 1,009 & 1,029 & 1,033 & 1,031 & 1,013 & 1,046 & 0,948 & 1,026 & 1,023 & 1,022 & 1,016 & 1.038 \\
\hline Th & 0,003 & 0,002 & 0,002 & 0,002 & 0,001 & 0 & 0 & 0 & 0 & 0,001 & 0,001 & 0,001 & 0,002 & 0,003 & 0 & 0 & 0 & 0 & 0.001 \\
\hline $\mathrm{db}$ & . & 0 & 0 & 0,002 & 0,003 & 0,002 & 0,001 & 0 & 0,003 & 0,001 & 0 & 0,001 & 0 & 0,003 & 0,001 & 0,003 & 0,002 & 0 & 0.002 \\
\hline 7 & 0,791 & 0,795 & 0,800 & 0,815 & 0,813 & 0,776 & 0,819 & 0,853 & 0,831 & 0,829 & 0,826 & 0,855 & 0.781 & 0,839 & 0,841 & 0,774 & 0,811 & 0,846 & 0,813 \\
\hline Nd & 0,001 & 0,002 & 0 & 0,001 & 0,002 & 0,001 & 0,003 & 0,002 & 0,001 & 0,002 & 0,002 & 0.003 & 0.003 & 0,002 & 0,002 & 0,002 & 0,002 & 0,003 & 0,001 \\
\hline Sm & 0,004 & 0,004 & 0,002 & 0,006 & 0,006 & 0,008 & 0,006 & 0,006 & 0,005 & 0,004 & 0.004 & 0,004 & 0,004 & 0,005 & 0,004 & 0,006 & 0,006 & 0,005 & 0,005 \\
\hline Gd & 0,042 & 0,038 & 0,034 & 0,039 & 0,040 & 0,038 & 0,029 & 0,028 & 0,026 & 0,024 & 0,024 & 0.024 & 0,024 & 0.025 & 0,022 & 0,033 & 0.035 & 0.027 & 0,022 \\
\hline Dy & 0,052 & 0,044 & 0,047 & 0,049 & 0,054 & 0,046 & 0,035 & 0,033 & 0,028 & 0,026 & 0,031 & 0.029 & 0,033 & 0.030 & 0,026 & 0,040 & 0.042 & 0.032 & 0,022 \\
\hline Er & 0,044 & 0,042 & 0,045 & 0,043 & 0,046 & 0,043 & 0,029 & 0,030 & 0,027 & 0,027 & 0,028 & 0,028 & 0,031 & 0.029 & 0,027 & 0,036 & 0,033 & 0.029 & 0,026 \\
\hline $\mathrm{Yb}$ & 0.045 & 0,046 & 0,050 & 0,038 & 0,042 & 0,039 & 0,030 & 0,031 & 0,030 & 0,029 & 0,031 & 0,091 & 0,034 & 0,033 & 0,031 & 0,035 & 0,030 & 0,029 & 0,030 \\
\hline TOTAL & 2,018 & 1,992 & 1,992 & 1,996 & 2,003 & 1,979 & 1,980 & 1,992 & 1,978 & 1,976 & $1,97 B$ & 1,989 & 1,966 & $2,(1) 3$ & 1,982 & 1,973 & 1,063 & 1,987 & 1,969 \\
\hline
\end{tabular}

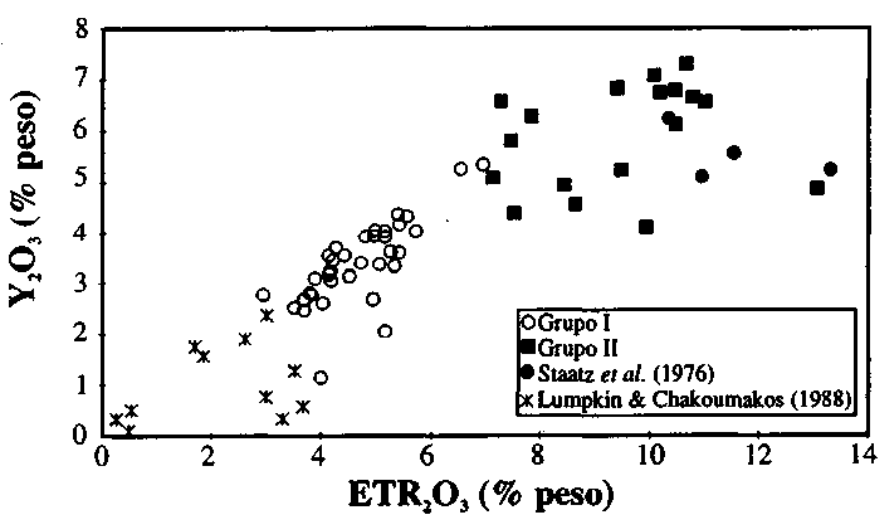

Figura 7 - Variaçāo nos conteúdos de $\mathrm{Y}_{2} \mathrm{O}_{3}$ e $\mathrm{ETR}_{2} \mathrm{O}_{3}$ na torita analisada e comparaçäo com alguns dados da literatura.

Os elevados conteúdos em $\mathrm{UO}_{2}$ e $\mathrm{ThO}_{2}$ nos cristais de zircão estudados devem-se à atuação das soluções sólidas zircão - uraninita e zircão - tonta. Os teores máximos observados correspondem a um máximo de $0,75 \%$ mol de $\mathrm{USiO}_{4}$ e $4,17 \%$ mol de $\mathrm{ThSiO}_{4}$ em solução sólida no zircão, valores que se localizam dentro dos campos de estabilidade propostos por Mumpton \& Roy (1961) para as soluções sólidas limitadas existentes entre zircão -uraninita (máximo de $4 \pm 2$ $\%$ mol de $\mathrm{USiO}_{4}$ no zircão) e zircão - torita (máximo de $4 \pm 2 \%$ mol de $\mathrm{ThSiO}_{4}$ no zircão).

Uma das principais substituições conhecidas no zircão é a que rege a solução sólida com a xenotima (Speer 1982, Burt 1989, Deer et al. 1997):

$$
(\mathrm{ETR}, \mathrm{Y})^{3+}{ }_{\mathrm{A}}+\mathrm{P}_{\mathrm{B}}^{5+} \Leftrightarrow \mathrm{Zr}^{4+}{ }_{\mathrm{A}}+\mathrm{Si}^{4+}{ }_{\mathrm{B}}(1)
$$

No caso da Subprovíncia Paranã, o conteúdo em $\mathrm{P}_{2} \mathrm{O}_{5}$ no zircão é, em geral, baixo ou nulo (tabela 1), indicando que a substituição (1) não é a única responsável pela entrada de cátions trivalentes na estrutura do mesmo.

Pointer et al. (1988a), estudando torita do granito Ririwai, Nigéria, propõem uma substituição do tipo:

$$
\mathrm{R}^{n+}{ }_{\mathrm{A}}\left(\mathrm{SiO}_{n} \mathrm{OH}_{4-n}\right)^{n-}{ }_{\mathrm{B}} \Leftrightarrow \mathrm{Th}^{4+}{ }_{\mathrm{A}}\left(\mathrm{SiO}_{4}\right)^{4-}{ }_{\mathrm{B}}(2)
$$

que explicaria a entrada de cátions com valência $n<4$ na estrutura da torita pela substituição do oxigénio por $\mathrm{OH}$ no sítio tetraédrico. Como a torita e o zircão são isoestruturais, os elementos envolvidos nesta substituição apresentam a mesma valência e ocupam os mesmos sítios estruturais, propõe-se uma substituição semelhante para explicar a entrada de cátions trivalentes na estrutura do zircão:

$(\mathrm{ETR}, \mathrm{Y})^{3+}{ }_{\mathrm{A}}\left(\mathrm{SiO}_{3} \mathrm{OH}\right)^{3--} \Leftrightarrow \mathrm{Zr}_{\mathrm{A}}^{4+}\left(\mathrm{SiO}_{4}\right)^{4-}{ }_{\mathrm{B}}(3)$.

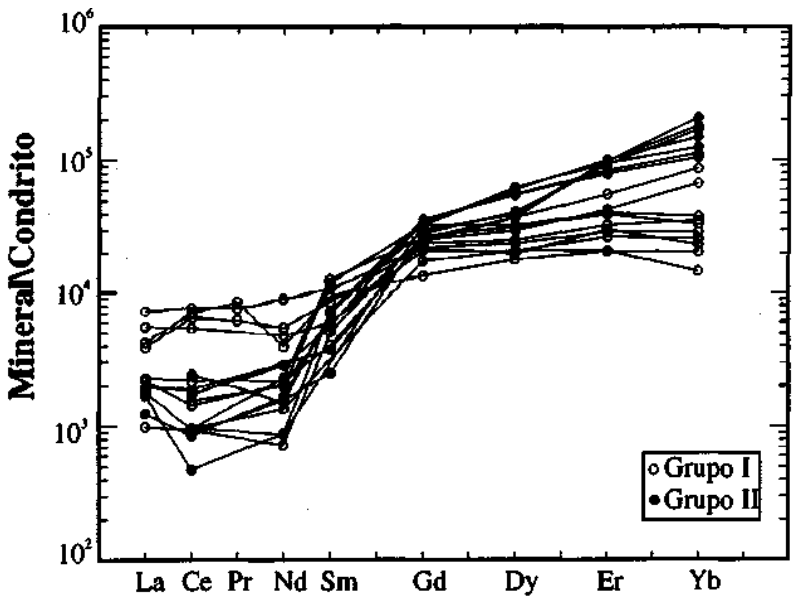

Figura 8 - Padróes de ETR normalizados ao condrito da torita dos grupos I e II.

que é favorecida pela constatação da existência de pequenas quantidades de $\mathrm{OH}$ no zircão.

Xenotima A xenotima e o zircão relacionam-se através da substituição (1) (Speer 1982, Robinson 1987, Deer et al. 1997), que governa a solucão sólida entre ambos. O baixo conteúdo de $\mathrm{ZrO} 2$ da xenotima estudada (abaixo do limite de deteç̧ão) mostra que a substituição (l) não é atuante nas mesmas. As principais substituições na xenotima podem ser observadas na figura 11. Os dados de xenotima estudada situam-se próximos ou sobre o eixo $\mathrm{X}$, mostrando que a diminuição dos conteúdos de ETR, Y e P não se deve às solucões sólidas xenotima -huttonita, xenotima - torita e xenotima - coffinita, pois, neste caso, haveria um maior conteúdo em Si que o observado. Presume-se que a retirada de $\mathrm{Y}$ e $\mathrm{P}$ da estrutura da xenotima deva-se à metamictização incipiente da mesma, e que os elevados conteúdos de ETR devam-se à substituição de Y por ETR no sítio octaédrico.

Torita Os elevados teores de UOi em torita dos grupos I e II e $\mathrm{ZrO}_{2}$ em torita do grupo I correspondem a um conteúdo máximo de $8,8 \%$ mol de $\mathrm{USiO}_{4}$ e $6,6 \%$ mol de $\mathrm{ZrSiO}_{4}$ em solução sólida. De modo geral, esses conteúdos caem dentro dos campos de estabilidade propostos por Mumpton \& Roy (1961) entre torita - uraninita (máximo de

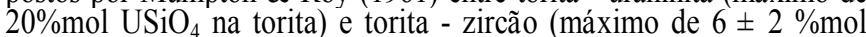
$\mathrm{ZrSiO} 4$ na torita). Uma análise de torita do grupo I apresenta teor anómalo de $\mathrm{ZrO}_{2}(10 \%)$, que implica na presenca de até $14 \%$ molar de $\mathrm{ZrSiO}_{4}$ em solução sólida, o que ultrapassa o limite de estabilidade proposto por Mumpton \& Roy (1961). Provavelmente este valor se deve a um intercrescimento entre zircão e torita ou à presença de 
Tabela 3 - Dados analíticos mais representativos de tonta dos grupos I e H. A fórmula estrutural foi calculada com base em quatro oxigênios.

\begin{tabular}{|c|c|c|c|c|c|c|c|c|c|c|c|c|c|c|c|c|c|c|c|}
\hline \multicolumn{12}{|l|}{ Grupo I } & \multicolumn{8}{|c|}{ Grupo II } \\
\hline Amostre & 1 & 2 & 3 & 4 & 5 & 6 & 7 & 8 & 9 & 10 & 11 & 12 & 13 & 14 & 15 & 16 & 17 & 18 & 19 \\
\hline $\mathrm{SiO}_{2}$ & 13,72 & 12,90 & 14,18 & 19,67 & 14,98 & 14.55 & 13,65 & 15,78 & 16,53 & 18,21 & 18,23 & 15,22 & 18,45 & 16,58 & 14,77 & 13,79 & 12,76 & 14.51 & 13,75 \\
\hline $\mathrm{roy}_{2}$ & f.d. & n.d. & n.d. & 10,01 & o.d. & n.d. & a.d. & घ.d. & n.d. & n.d. & D. C & 4,7 & 3,76 & n.d & n. & 4,14 & 3.2 & n. & 0,84 \\
\hline $\mathrm{O}_{3}$ & 2,82 & 4,02 & 0,93 & 1,24 & 1,42 & 1,22 & 4,09 & 3,71 & 0,65 & 0,34 & 0,18 & 2,13 & 2,02 & 2,37 & 1,98 & 4,20 & 2,98 & 2,51 & 2,69 \\
\hline jou & 1,03 & 1,00 & 5,29 & 1,43 & 8,93 & $8,6]$ & 0,20 & 0,78 & 11,50 & 10,79 & 12,43 & 2,17 & 1,10 & 0,67 & 2,68 & 2,33 & 2,44 & 7,53 & 6.61 \\
\hline The & 52,40 & 46,67 & 53,24 & 39,47 & 48,57 & 45,39 & 47.18 & 38,35 & 44,48 & 41,55 & 44,54 & 27,26 & 34,06 & 38,53 & 37,68 & 32,46 & 25,82 & 41,19 & 39,74 \\
\hline $\mathrm{Y}_{2} \mathrm{O}$ & 5,26 & 5,35 & 3.55 & 3,94 & 3,05 & $2,8 \mathrm{~d}$ & 4,33 & 3,92 & 3,40 & 2,68 & 1,14 & 6.56 & 6,78 & 7,08 & 7,30 & 4,12 & 4,87 & 4,57 & 5,24 \\
\hline & 0,07 & 0,07 & 0,05 & 0,06 & 0,18 & 0,16 & 0,14 & n.d. & 0.15 & 0.28 & 0,49 & n.d. & 0,08 & n.d. & n.d. & 0.07 & 0,40 & 0,03 & 0,05 \\
\hline $\mathrm{Ce}_{2} \mathrm{O}$ & 0.10 & 0,15 & 0,24 & 0,15 & 0,59 & 0,64 & 0,25 & 0,12 & 0,66 & 0,79 & 1,19 & 0,25 & 0,19 & 0,69 & 0,12 & 0,05 & 0,79 & 0,10 & 0,09 \\
\hline A & 0,02 & 0,02 & n.d. & 0,17 & 0,11 & 0,16 & 0,11 & 0,03 & 0,09 & 0,12 & 0,29 & n.d. & 0,16 & 0,01 & n.d. & n.d. & 0,23 & n.d. & n.d. \\
\hline$N$ & 0,17 & 0,16 & 0,25 & 0,14 & 0,37 & 0,28 & 0,13 & 0,14 & 0,40 & 0,66 & 0,77 & 0,23 & n.d. & 0,10 & 0,18 & 0,07 & 0,44 & 0,06 & 0,12 \\
\hline $\mathrm{O}_{3}$ & 0,30 & 0.17 & 0,15 & 0,08 & 0,41 & 0,26 & 0,22 & 0,18 & 0,20 & 0,25 & 0,25 & 0,02 & 0,09 & 0,09 & n.d. & 0,04 & 0,27 & 0.17 & 0,16 \\
\hline & 0,83 & 0,76 & 0,83 & 0,68 & 0,69 & 0,58 & 1,08 & 0,98 & 0,71 & 0,70 & 0,29 & 1,03 & 0,79 & 0.76 & 1,01 & 1,05 & 1,50 & 1,16 & 1,07 \\
\hline D. & 1,47 & 1,47 & 1,19 & 1,22 & 0,79 & 0,63 & 1,40 & 1,53 & 0,94 & 0,78 & 0,22 & 1,74 & 1.47 & 1,50 & 1,65 & 2,38 & 2,72 & 2,18 & 2,46 \\
\hline & 1,43 & 1,74 & 0,88 & 1,12 & 0,60 & 0,56 & 1,22 & 1,18 & 0,75 & 0,78 & 0,20 & 2,62 & 2,52 & 2,52 & 2,63 & 2,59 & 2,73 & 2,13 & 2,42 \\
\hline & 2.15 & 240 & 0,94 & 135 & 0,40 & 0,48 & 0,94 & 1,01 & 0.72 & 0,58 & 0,23 & 5,13 & 5.16 & 4,99 & 5,04 & 3,69 & 3.97 & 2.81 & 3,09 \\
\hline TOTAL & 81,76 & 76,88 & 01,48 & 10,73 & 81,09 & 76,33 & 74,94 & 67,71 & 81,18 & 78,51 & 80,45 & 9,10 & 76,63 & 75,29 & 75,04 & 70,98 & 65,16 & 78,95 & 78,33 \\
\hline
\end{tabular}

Formula Estrutural Calculada com Base em Quartzo Oxigênios

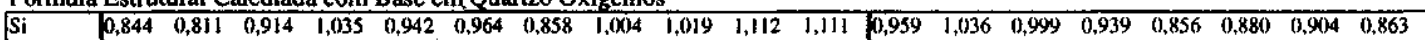

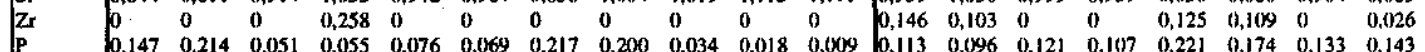

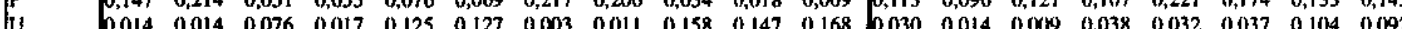

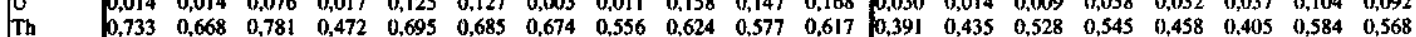

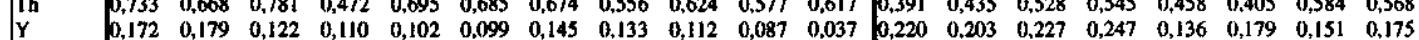

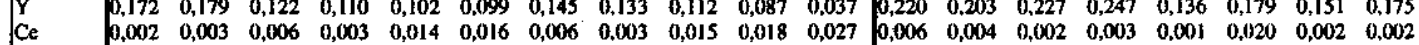

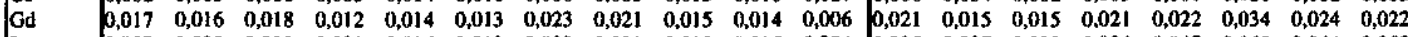

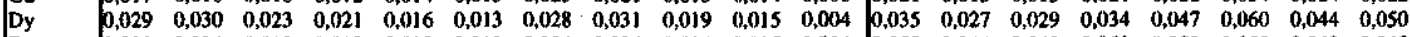

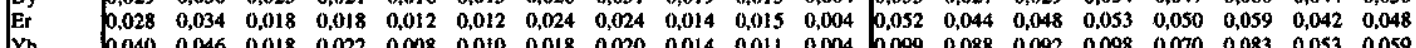
\begin{tabular}{|l|lllllllllllllllllllll} 
TOTAL & 2,026 & 2,013 & 2,027 & 2,023 & 2,004 & 2,009 & 1,996 & 2,003 & 2,024 & 2,014 & 1,987 & 2,072 & 2,065 & 2,070 & 2,085 & 2,018 & 2,040 & 2,041 & 2,048 \\
\hline
\end{tabular} n.d. - nato detcelado.

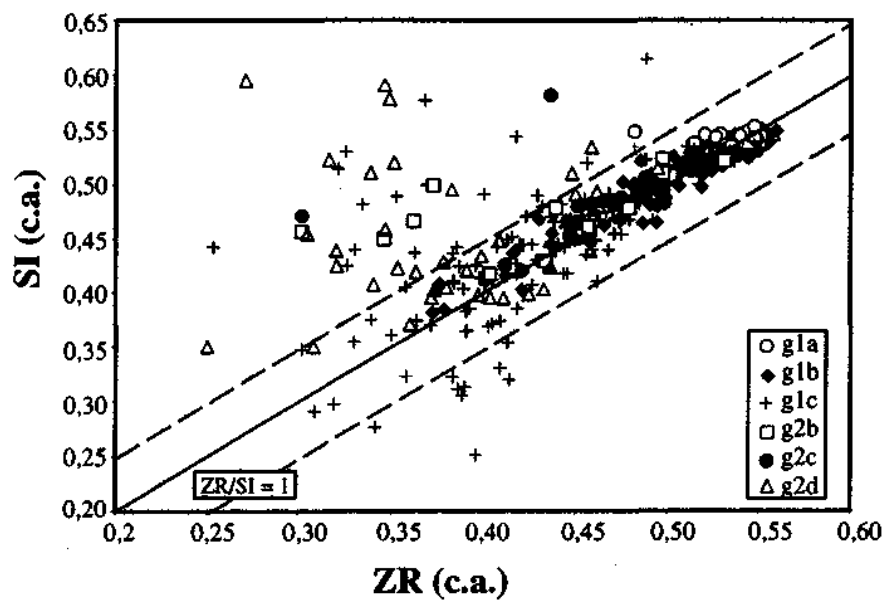

Figura 9 - Concentraçōes atômicas de $Z R(Z R=Z r+H f+U+Y+$ ETR) e $S I(S I=S i+P)$ nos cristais de zircão estudados.

microinclusões de zircão. Contudo, não deve ser descartada a hipótese de parte desse $\mathrm{ZrSiO}_{4}$ estar metaestável na estrutura da torita (Mumpton \& Roy 1961, Pointer et al. 1988a).

As correlações negativas entre $(\mathrm{ETR}+\mathrm{P})$ e $(\mathrm{Th}+\mathrm{Si})($ Fig. 12) e positiva entre Y e ETR (Fig. 13) indicam a atuação da substituição:

$(\mathrm{ETR}, \mathrm{Y})_{\mathrm{A}}^{3+}+\mathrm{P}_{\mathrm{B}}^{5+} \Leftrightarrow \mathrm{Th}_{\mathrm{A}}^{4+}+\mathrm{SI}^{4+}{ }_{\mathrm{B}}(4)$

que representa a solução sólida existente entre xenotima e torita (Lumpkin \& Chakoumakos 1988, Pointer et al. 1988a, Kamineni \& Lemire 1991). Entretanto, quando as análises são dispostas em um diagrama (Y + ETR) x P (em termos de átomos por fórmula unitária) (Fig. 14) constata-se que, mesmo havendo uma correlação positiva entre esses elementos, os pontos não se dispõem ao longo de uma linha $(\mathrm{Y}+\mathrm{ETR}) / \mathrm{P}=1$, de modo que a equação (4) não deve ser a única responsável pela entrada de $\mathrm{Y}$, ETR e P na estrutura da torita.

Pointer et al(1988a), estudando torita do Granito Ririwai, Nigéria, propuseram a existência de uma substituição do tipo:

$\left(\mathrm{Y}+\mathrm{ETR}^{3+}{ }_{\mathrm{A}}\left(\mathrm{SiO}_{3} \mathrm{OH}\right)_{\mathrm{B}}^{3-} \Leftrightarrow \mathrm{Th}^{4+}{ }_{\mathrm{A}}\left(\mathrm{SiO}_{4}\right)^{4}{ }_{\mathrm{B}}(5)\right.$

o que explicaria o excesso de $\mathrm{Y}$ e ETR em relação ao $\mathrm{P}$ pela entrada de água no sítio tetraédrico. Segundo esses autores a equação (2), semelhante à (5), explicaria a entrada de cátions $R^{\mathrm{n}+} \operatorname{com} \mathrm{n}<4$ na estrutura da torita.

Os baixos totais e a intensa metamictização dos cristais de torita indicam a presença de uma grande quantidade de água neste mineral O conteúdo, calculado por diferença de $100 \%$, varia entre 15 e $45 \%$, que é significativamente maior que os conteúdos apresentados por Speer (1982) como sendo os mais elevados da literatura (15\%). Isto

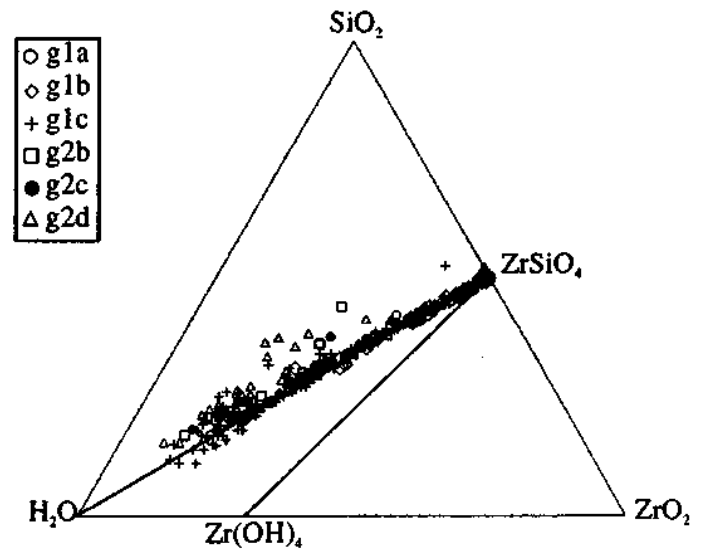

Figura 10 - Diagrama $\mathrm{SiO}_{2}-\mathrm{ZrO}_{2}-\mathrm{H}_{2} \mathrm{O}$ em base molecular (Mumpton \& Roy 1961) no qual estāo dispostos os dados de zircão. que se dispöem preferencialmente ao longo da linha $\mathrm{ZrSiO}_{4}-\mathrm{H}_{2} \mathrm{O}$.

sugere que a torita analisada é mais metamíctica que a torita da literatura ou trata-se de torogumita $-\mathrm{Th}\left(\mathrm{SiO}_{4}\right)_{1}-\mathrm{X}(\mathrm{OH})_{\mathrm{X}}$. A disposição das análises em um diagrama $\mathrm{SiO}_{2}-\mathrm{ThO}_{2}-\overline{\mathrm{H}}_{2} \mathrm{O}$ em base molecular (Mumpton \& Roy 1961, Speer 1982) (Fig. 15) mostra que, além da torita estudada ser anomalamente rica em água, ela vai estar essencialmente na forma molecular, inviabilizando a hipótese de que se trata de torogumita. Entretanto, assim como para o zircão, uma porção desta água deve estar na forma de hidroxila, favorecendo a substituição (5).

DISCUSSÃO Comportamento do zircão e da torita durante a evolução magmática. $Z I R C \tilde{A} O \mathrm{O}$ zircão dos granitos $\mathrm{gl} \mathrm{e}$ g2 apresenta um enriquecimento progressivo em $\mathrm{Y}_{2} \mathrm{O}_{3}$, $\mathrm{ETR}_{2} \mathrm{O}_{3}$ (principalmente ETRP), $\mathrm{ThO}_{2}$ e $\mathrm{UO}_{2}$ à medida que se processa a evolução magmática (Fig. 2 e 3 e tabela 1), fato que se reflete na diminuição da razão $(\mathrm{La} / \mathrm{Gd}) \mathrm{N}$ no zircão $(0,05-0,03$ entre gla e glc e $0,3-0,06$ entre g2b e g2d) (Fig. 4a e b). $\mathrm{O}$ zircão das fácies mais evoluídas possui composiçãoo que difere daquela de um zircão ideal, sendo mais suscetíveis à ação de processos tardi/pós-magmáticos, e apresenta um maior grau de metamictização que aquele das fácies menos evoluídas.

Botelho (1992) constatou que Y, U, Th e ETRP apresentam um caráter incompatível durante a evolução dos granitos gl. Na suile g2 U e ETRP possuem um caráter incompatível enquanto $\mathrm{Y}$ e Th não apresentam comportamento muito evidente durante a evolução magmática, constatações favorecidas pelo fato do zircão se tornar enriquecido nesses elementos entre gla eglce entre g2b e g2d. 


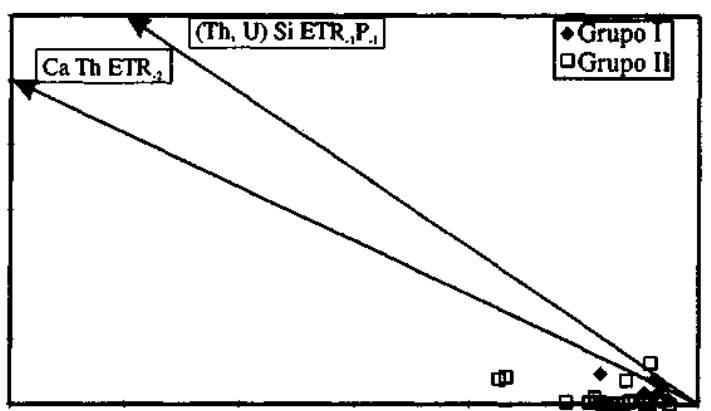

Figura II -Diagrama $(T h+U+S i)$ versus $(E T R+Y+P)$ de Franz et al. (1996). Os dados, em átomos por fómula unitária, foram multiplicados por quatro, em acordo com o apresentado pelo autor.

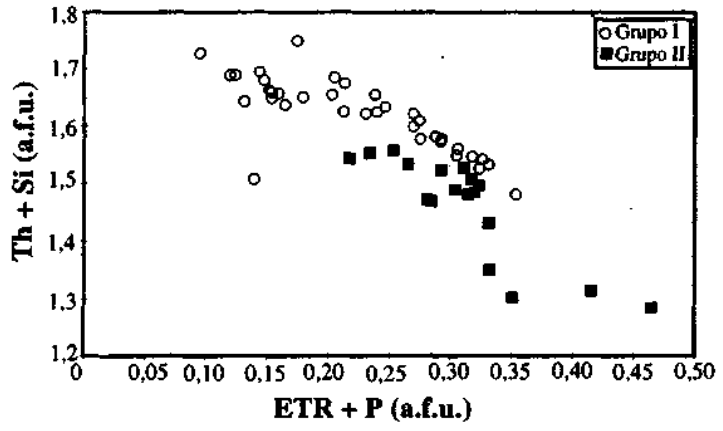

Figura 12 - Variação nos conteúdos de $(T h+S i)$ versus $(E T R+P)$ ent termos de átomos por fórmula unitária na torita estudada mostrando a substituição: $T h^{4+}{ }_{A}+S i^{4+}{ }_{B} \Leftrightarrow E T R^{3+}{ }_{A}+P_{B+}^{5+}$

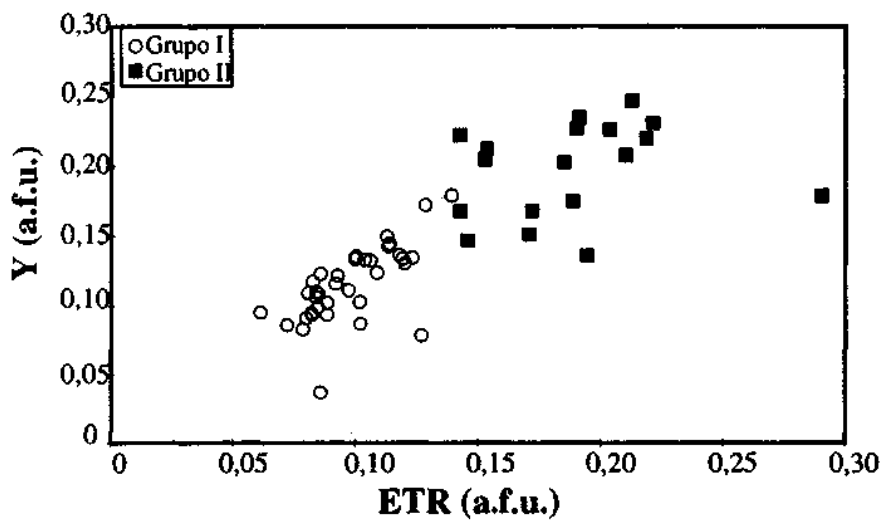

Figura 13 - Correlação positiva entre Ye ETR (em termos de átomos por fórmula unitária) mostrando a entrada conjunta desses elementos na estrutura da torita.

TORITA A torita foi encontrada apenas nas fácies mais evoluídas das suites gl e g2 (Teixeira 1998), sendo mais comum nos granitos gl, confirmando observações de Botelho (1992) de que os granitos gl são mais enriquecidos em Th que os granitos g2 e que este elemento apresentou um caráter incompatível durante a evolução magmática, tornando-se compatível apenas ao final da mesma, quando ocorre a precipitação da torita.

\section{Comportamento dos minerais durante a greisenização}

ZIRCÃO Segundo Botelho (1992), o enriquecimento do zircão das fácies mais evoluídas em Y e ETR deve-se à evolução magmática e não a processos tardi/pós-magmáticos. Entretanto, quando se compara os dados de zircão dos granitos, granitos greisenizados e greisens coletados em um mesmo ponto observa-se que os cristais encontrados em granitos greisenizados e greisens tendem a ser mais ricos em Y e ETR que os dos granitos (Fig. 16). Isto mostra que, embora a evolução magmática tenha influenciado na variação de Y e ETR no zircão (Fig. 3), houve reequilíbrio parcial do mesmo durante o evento hidrotermal. $\mathrm{O}$ zircão é comumente considerado um mineral resistato e imune à alteração. Entretanto, sob determinadas condições hidrotermais, mineral pode ser destruído ou ter sua composição química alterada. Alderton et al. (1980), estudando granitos alterados do sudeste da Inglaterra,

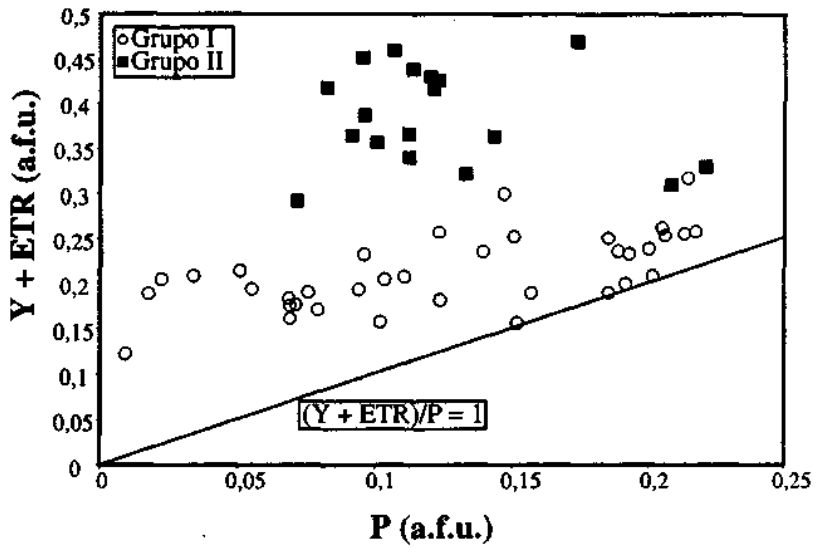

Figura 14 - Variação nos conteúdos de $(Y+E T R)$ e $P$ (em termos de átomos por fórmula unitária) na torita estudada.

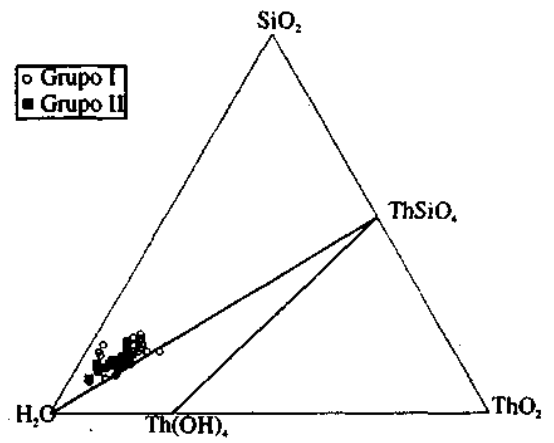

Figura 15 - Diagrama $\mathrm{SiO}_{2}-\mathrm{ThO}_{2}-\mathrm{H}_{2} \mathrm{O}$ em base molecular (Mumpton \& Roy 1961) onde estão dispostos os dados analíticos de torita dos grupos I e II.

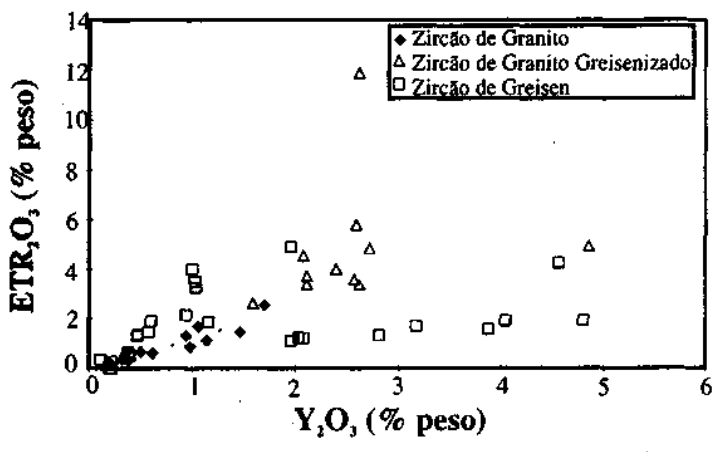

Figura 16 - Relação entre os conteúdos de $\mathrm{Y}_{2} \mathrm{O}_{3}$ e $\mathrm{ETR}_{2} \mathrm{O}_{3}$ em zircão de granitos e de granitos greisenizados e greisens relacionados.

observaram que, durante o processo de turmalinização, há uma diminuição significativa no conteúdo de zircônio no zircão. Entretanto, esses autores não observaram a influência de processos como greisenização, cloritização e argilização sobre os cristais estudados.

O zircão do Granito Ririwai, Nigéria, foi afetado de várias maneiras pelos eventos hidrotermais atuantes nessas rochas (Pointer et al. 1988b). Estes autores observaram que o zircão de rochas metassomáticas estão corroídos ou apresentam "manchas escuras" nas quais o zircônio foi substituído por Y, U e Th. Bilal (1991), estudando as rochas graníticas do Maciço Sucuri, observou que o zircão de albititos e granitos greisenizados é mais rico U, Th, Y, P, Ca e Fe. Segundo esses autores, o transporte de $\mathrm{Zr}, \mathrm{Y}, \mathrm{U}$ e Th pelo fluido hidrotermal requer a complexação desses elementos com ânions ou grupos aniônicos do tipo $\mathrm{CO}_{3}^{-}, \mathrm{HPO}_{4}^{2-}, \mathrm{Cl}^{-}, \mathrm{F}^{-}$, de modo que a composição do fluido hidrotermal é fundamental para promover a quebra do zircão e a lixiviação dos elementos.

O ácido fluorídrico (HF) é o único ácido capaz de dissolver o zircão, ainda que com dificuldade (Dietrich 1968, Krogh 1973, ambos apud Rubin et al. 1989), de modo que a dissolução do zircão e lixiviação de zircônio envolvem a presença de $\mathrm{F}^{-}$no fluido hidrotermal. A presença de uma grande quantidade de fluorita nos greisens estudados e a íntima associaçã̃o deste mineral com o zircão (o zircão é comumente encon- 
trado como inclusões na fluorita) mostram que o fluido hidrotermal era enriquecido em $\mathrm{F}^{-}$e que a presença deste ânion no mesmo foi responsável pela alteração química do zircão durante a greisenização, com o seu enriquecimento em Y e ETR.

XENOTIMA Foi constatada a presença de xenotima apenas nos greisens desenvolvidos sobre a fácies gl $b$. Nos granitos glb foram observados numerosos minerais magmáticos portadores de ETR, YEP como apatita, allanita, monazita e zircão (Teixeira 1998). Entretanto, apatita $\mathrm{e}$ allanita não foram encontradas nos greisens, sugerindo a destruição destes minerais durante o evento hidrotermal. Deste modo, a greisenização provocou a liberação de elementos como $\mathrm{Y}^{3+}, \mathrm{P}^{5+}$ e $\mathrm{ETR}^{3+}$ pela destruição de minerais preexistentes, criando condições para a precipitação de xenotima secundária nos greisens desenvolvidos sobre os granitos glb.

TORITA - A torita torna-se enriquecida em $\mathrm{Y}_{2} \mathrm{O}_{3}$ e $\mathrm{ETR}_{2} \mathrm{O}_{3}$ com a greisenização (Fig. 7 e 8), fato que é acompanhado por uma diminuição no conteúdo de Th, e no tamanho e quantidade de torita até o seu desaparecimento quase total nos greisens (Teixeira 1998).

Y, Th e ETR são comumente considerados como elementos imóveis, entretanto, sob determinadas composições do fluido hidrotermal, Y e Th podem ser mobilizados dos seus sítios originais (ver discussão sobre o zircão). Um comportamento semelhante foi constatado em relação aos ETR. Para que haja o transporte desses elementos, o fluido hidrotermal deve ser enriquecido em $\mathrm{HCO}_{3}^{-}, \mathrm{CO}_{3}^{-}, \mathrm{F}^{-}, \mathrm{Cl}^{-}$, $\mathrm{HSO}_{4}^{-}$ou $\mathrm{SO}_{4}{ }^{2-}$. Entretanto para que possam ser transportados a longas distâncias, os ETR devem estar na forma de compostos altamente solúveis e de difícil dissociação (Kosterin 1959, McLennan \& Taylor 1979, Alderton et al. 1980, Baker 1985). A presença de fluorita e fluorcarbonatos nos greisens sugere que $\mathrm{F}^{-}$e $\mathrm{CO}_{3}^{2-}$ eram compostos comuns nos fluidos greisenizantes, capazes portanto de provocar a lixiviação/mobilização do Y, Th e ETR e, consequentemente, o enriquecimento da torita em Y e ETR e seu empobrecimento em Th durante a greisenização.

CONCLUSÕES - Nos maciços estudados os principais minerais acessórios concentradores de ETRP são zircão, xenotima e torita.

\section{Referências}

Ahrens L. H., Cherry R. D., Erlank A. J. 1967. Observation on the Th-U relalionship in zircons from granitic rocks and from kimberlilcs. Geochimica et Cosmochimica Acta. 31:2379-2387.

Alderton D. H.M., Pearce J. A., Potts P. J. 1980. Rarc earth clement mobility during granite alteration: evidence from southwest England. Earth and Planetary Science Letters, 49:149-165.

Åmli R. 1975. Mineralogy and rare-earth geochemistry of apatite and xenotimc from the Gloserheia Granite Pegmalite, Froland, southern Norway. American Mineralogist. 60:607-620.

Åmli R. \& Griffin W. L. 1975. Microprobe analysis of REE minerais using cmpirical correction factors. American Mineralogist, 60:599-606.

Baker J. H. 1985. Rare earlh and other trace element mobility accompanyng albitization in a Proterozoic granite, W. Bergslagen, Sweden. Mineralógica! Magazine, 49:107-115.

Bilal E. 1991. Elude de deux massifs de Ia province granitique stanniffere de I'Etat de Goiás (Brèsil) et des formations métasomatiques associés aux minéralisations en Sn et Be.. École Nationale Superieure dês Mines de Saint Éticnne et École Nationale Supérieure des Mines de Paris, Paris, Thèsc de Doctorat, 360p.

Botelho N. F. 1984. O granito Pedra Branca (Goiás) e as mineralizações de estanho associadas. Instituto de Geociências, Universidade de Brasília, Brasília, Tese de Mestrado, 258p.

Botelho N. F. 1992. Les ensembles granitiques subalcalins a peralumineux mineralisés en Sn et In de Ia sous-province Paranã état de Goiás, Brèsil, Université de Paris VI, Paris, Thèse de Doctorat, 344p.

Botelho N. F. \& Pimentel M. M. - 1993 - Geocronologia Rb-Sr das fases intrusivas do Maciço Granítico da Pedra Branca, Província Estanífera de Goiás. In: Congresso Brasileiro de Geoquímica, IV, Brasília, 1993, Boletim de Resumos Expandidos, p. 253-255.

Botelho N.F. \& Teixeira L.M. 1996. Apatila rica em terras raras c ítrio e sua transformação cm britholita (Ca, REE, Y)s[(Si, P) CuMOH, F) em granitos da Província Estanffcra de Goiás. In: Congresso Brasileiro de Geologia, XXXIX, Salvador, 1996 Anais... Salvador, v. 3 , p60.

Burt D. M. 1989. Composilional and fase relations among rare-earlh elcments minerais. In: Lipin, B. R e McKay, G. A (ed.) Reviews in Mineralogy, vol. 21, New York, The Mineralógica! Society of America, 259-308.

Cathelineau M. 1987. U-Th-REE mobility during albilization and quartz dissolution in granitoids: evidence from southeast French Massif Central. Bulletin de Mineralogie, 110:249-259.

Deer W. A., Howic R. A., Zussman J. 1997. Rock Forming Minerais - volume la -Orthosilicates, London, The Gcological Society, p. 418-442.

Demartin F., Pillati T., Diella V., Donzelli S., Genlile P., Gramaccioli C. M. 1991. The chemical composition of xcnotime from fissurcs and pegmatites in the Alps. Canadian Mineralogist, 29:69-75.

Franz G., Andrehs G., Rhede D. 1996. Crystal chemistry of monazite and xcnotime from Saxothuringian-Moldanubian melapcliles, NE Bavaria, Germany. European Journal of Mineralogy, 8:1097-1118.

Heaman L. M., Bowins R. \& Crockct J. 1990. The chemical composition of igncous zircon suites: implications for geochemical tracer studies. Geochimica et Cosmochimica Acta, 54:1597-1607.

Kamincni D. C. 1986. Distribution of uranium, thorium and rare-earth elcments in the Eye-Dashwa Lakes Pluton - a study of some analoguc elements. Chemical Geology, 55:361-373.
Destes, apenas o zircão foi encontrado em todas as fácies, tanto em granitos quanto em greisens.

$\mathrm{O}$ zircão apresenta aumento progressivo nos conteúdos de $\mathrm{UO}_{2}$, $\mathrm{ThO}_{2}, \mathrm{Y}_{2} \mathrm{O}_{3}$ e $\mathrm{ETR}_{2} \mathrm{O}_{3}$ com a evolução magmática. Cristais de zircão envolvidos na greisenização também apresentam enriquecimento em Y e ETR, mostrando que mesmo sendo considerado como mineral resistato, ele também foi afetado pelo evento hidrotermal. O zircão da suite g 1 apresenta dois trenas de enriquecimento, com razões $\mathrm{Y}_{2} \mathrm{O}_{3} / \mathrm{ETR}_{2} \mathrm{O}_{3}$ maiores e menores que 1 respectivamente. $\mathrm{O}$ zircão de g2 possui razão $\mathrm{Y}_{2} \mathrm{O}_{3} / \mathrm{ETR}_{2} \mathrm{O}_{3}$ geralmente maior que 1 . A entrada de U e Th na estrutura do zircão deve-se à atuação das soluções sólidas zircão - uraninita e zircão - torita respectivamente. A entrada de Y e ETR deve-se em parte à solução sólida zircão - xenotima e em parte à substituição $\mathrm{O}^{2-} \Leftrightarrow \mathrm{OH}^{-}$no tetraedro de sílica.

Existem dois tipos de xenotima diferenciáveis entre si através dos seus conteúdos em ETRP: a xenotima do grupo I é mais rica nesses elementos que a xenotima do grupo II. A principal substituição na xenotima deve-se à entrada de ETR em substituição ao Y no sítio octaédrico.

Existem dois tipos de torita: grupo I - encontrada em granitos, e grupo II - encontrada em granitos greisenizados e greisens. A torita do grupo II é mais rica em Y e ETR que a do grupo I, de modo que há um enriquecimento da torita nesses elementos durante o evento hidrotermal. Os elevados conteúdos em $\mathrm{UO}_{2}, \mathrm{ZrO}_{2}$ na torita devem-se, respectivamente, à ação das soluções sólidas torita - uraninita, torita zircão, enquanto os de $\mathrm{Y}_{2} \mathrm{O}_{3}$ e ETR $\mathrm{O}_{3}$ relacionam-se à solução sólida torita - xenotima, embora parte da entrada de cátions trivalentes na estrutura deste mineral deva-se à substituição de $\mathrm{O}^{2-}$ por $\mathrm{OH}^{-}$no tetraedro de sílica.

Agradecimentos Ao $\mathrm{CNPq}$ pelo financiamento à pesquisa (processo ${ }^{\circ} 400620 / 95$ ), bem como aos professores Silvio Roberto Farias Vlach e José Carlos Gaspar pelas sugestões e correções da Dissertação de Mestrado de L. M. Teixeira, Profa. Márcia Ábrahão Moura pela leitura crítica do manuscrito e a dois revisores anónimos da RBG pelas sugestões e críticas.

Kamincni D. C. \& Lemirc, R. J. 1991. Thorilc in fault zoncs of a granitic pluton, Atíkokan, Canada implications for nuclear fuel wastc disposal. Chemical Geology, 90:133-143.

Kosterin A. V. 1959. The possible modes of transport of the rare earth by hydrothermal solutions. Geochemistry, 4:381 - 387

Lumpkin G. R. \& Chakoumakos, B. C. 1988. Chemistry and radiation effects of thorite-group minerais from the Harding pegmatite, Taos County, New México. American Mineralogist, 73:1405-1419.

Marel H.W. \& Beutelspacher H. 1976. Atlas of Infrared spectroscopy of Clay Minerais and their admixturcs. Amsterdam, Elsevier Scientific Publishing Company, 396p.

Marini O. J. \& Botelho N. F. 1986. A província de granitos estaníferos de Goiás. Revista Brasileira de Geociências, 16:119-131.

Marini O. J., Botelho N. F, Rossi Ph. 1992. Elementos terras raras em granitóides.da província estanífera de Goiás. Revista Brasileira de Geociências, 22:61-72.

McLennan S. M. \& Taylor S. R. 1979. Rare-earth element mobility associated with uranium mineralisation. Nature, 282:247-250.

Mumpton F. A. \& Roy R. 1961. Hydrothermal stability studies of zircon-thorite group. Geochimica et Cosmochimica Acta. 21:217-238.

Padilha J. L \& Laguna A. M. G. 1984. Geologia dos granitos da Pedra Branca, Mocambo, Mangabeira e Serra do Mendes - Goiás. In: Simpósio de Geologia do Centro Oeste, $1^{\circ}$. Goiânia, 1984, Anais..., Goiânia, p. 622-643.

Pimentel M. M., Heaman L, Fuck R. A \& Marini O. J. 1991. U-Pb zircon geochronology of prccambrian tin-bearing continental-type acid magmatism in central Brazil. Precambrian Research, 52:321-335.

Pointer C. M., Ashworth J. R., Ixer R. A. 1988a. The zircon-thorilc mineral group in mctasomatized granite, Ririwai, Nigéria, 1 - gcochemistry and mctastablc solid solution of thorilc and coffinilc. Mineralogy and Petrology, 38:245-262.

Pointer C. M., Ashworth J. R., Ixer R. A. 1988b. The zircon-thorite mineral group in melasomalizcd granitc, Ririwai, Nigéria. 2 - Zoning, alteration and cxsolulion in zircon. Mineralogy and Petrology, 39:21-37.

Robinson G. W. 1987. Zircon-xenotime intergrowths. Rocks and Minerais, 62:118.

Rubin J. N., Henry C. D., Price J. G. 1989. Hydrothermal zircons and zircon overgrowths, Sierra Blanca Peaks, Texas. American Mineralogist, 74:865-869.

Speer J.A. 1982. Zircon: chaptcr 3, The actinide orthosilicates, chapter 4. In: P. H. Ribbe (ed.) Orthosilicates. Reviews in Mineralogy, New York, Mineralogical Society of America, 67-135.

Staatz M. H., Adams J. W., Wahlberg J. S. 1976. Brown, yellow, orange, and greenish-black thorites from lhe Seerie pegmatite, Colorado. Journal Research U. S. Geológica! Survey. 4:575-582.

Teixeira L. M. 1998. Caracterização dos minerais portadores de Terras Raras em granitos da Subprovíncia estanifera Paranã - Goiás. Instituto de Geociências, Universidade de Brasília, Brasília, Dissertação de Mestrado, 223p. 